\title{
Cerámicas emirales y califales de Murcia, calle Pascual (siglos IX-XI)
}

\author{
The emiral and caliphal ceramics of Murcia, Pascual St. ( $9^{\text {th }}-11^{\text {th }}$ centuries) \\ Pedro Jiménez Castillo*, Manuel Pérez Asensio** \\ Recibido 17/4/2018 - Aprobado 24/7/2018
}

\begin{abstract}
RESUMEN
En este trabajo se estudian algunos de los hallazgos cerámicos procedentes de la excavación arqueológica de un solar en la ciudad de Murcia. La sucesión estratigráfica del depósito analizado, que alcanzó los $-5.25 \mathrm{~m}$ de profundidad, se remontaba desde niveles modernos hasta los horizontes de ocupación más antiguos. Para algunos de estos contamos con dataciones procedentes de análisis de Carbono 14 efectuados sobre restos orgánicos y de algún hallazgo numismático. Gracias a todo ello y al examen comparativo con otros yacimientos, hemos podido establecer una secuencia de la evolución de las producciones alfareras entre los siglos IX y XI. El estudio de estas cerámicas también nos ha proporcionado valiosa información acerca de los orígenes de la propia ciudad de Murcia y de la evolución de la sociedad que la pobló en los primeros siglos de su historia.
\end{abstract}

Palabras clave: Al-Andalus, cerámica emiral, cerámica califal, Murcia islámica, producción alfarera

\section{Introducción}

En este trabajo vamos a ocuparnos de las producciones cerámicas de un periodo histórico que se extiende desde el momento de la fundación de la ciudad (año 825) hasta fines de época califal, mal conocidas a nivel de alAndalus en general y de Murcia en concreto ${ }^{1}$.

\begin{abstract}
In this paper, some of the ceramic finds from the archaeological excavation of a plot in the city of Murcia are studied. The stratigraphic succession of the analyzed deposit, which reached $-5.25 \mathrm{~m}$ deep, dates back from modern levels until the horizons of earlier occupation. For some of these we have dates obtained from $14 \mathrm{C}$ analysis of some organic remains and a numismatic find. Taking into account all of these data and the comparative analysis with other sites, we have set a sequence of evolution of the pottery throughout a period between the $9^{\text {th }}$ and $11^{\text {th }}$ centuries. The study of these ceramics has also provided valuable information about the origins of the city of Murcia and its social evolution during the first centuries of its history.
\end{abstract}

Key words: Al-Andalus, emiral ceramics, caliphal ceramics, Islamic Murcia, pottery production

Para ello nos basaremos fundamentalmente en los resultados proporcionados por una excavación llevada a cabo por nosotros en pleno casco histórico, concretamente en la calle Pascual (Fig. 1). Por tanto, el objetivo inmediato de este trabajo es tratar de aproximarnos a la evolución de los tipos, decoraciones y tratamientos, de la cerámica de la Murcia

\footnotetext{
* Arqueólogo. Escuela de Estudios Árabes (CSIC) ${ }^{* *}$ Arqueólogo.

1. Este trabajo tiene su origen en las dos ponencias que expusimos en el XVII Congreso de la Asociación de Ceramología celebrado en Ojós (Murcia), del 13 al 16 de noviembre 2014, organizado por el Dr. Jaume Coll y D. Juan García Sandoval. Queremos agradecer a varios colegas sus aportaciones a este trabajo: a D. Alejandro Márquez, por su ayuda en la realización de los dibujos; al Dr. Salvador Martín y a la Dra. Carolina Doménech por sus apreciaciones sobre una moneda de vidrio; a Dña. Victoria Amorós por la lectura del texto, sus correcciones y sus siempre constructivas críticas; finalmente al Dr. Julio Navarro por su magisterio continuo y por facilitarnos la documentación original de las excavaciones por él dirigidas y, en particular, del alfar de S. Nicolás. Asimismo, agradecemos a la Dra. Miriam Gómez-Paccard su implicación a través de las analíticas en el estudio de la secuencia cerámica que presentamos.
} 


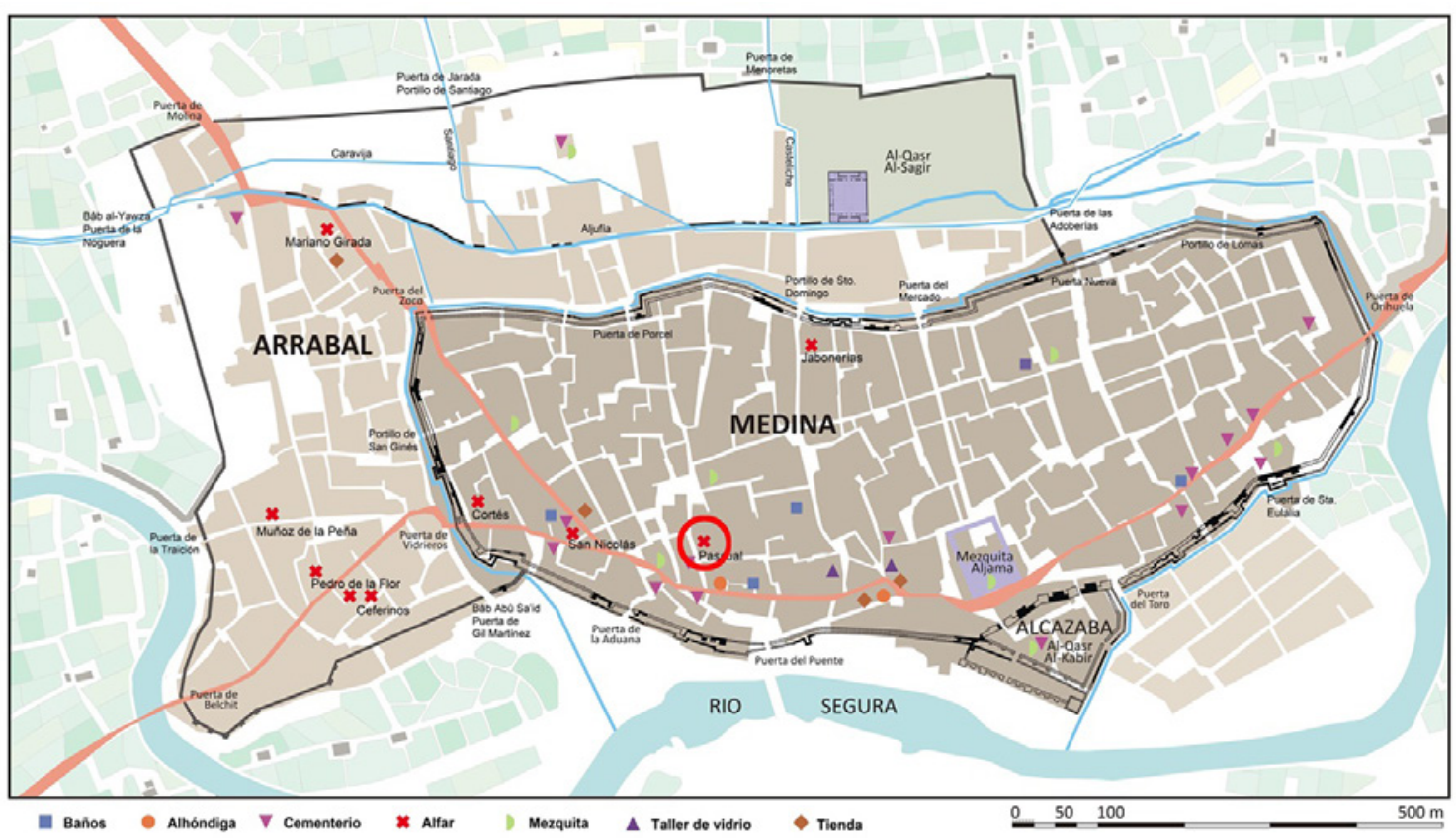

Fig. 1. Croquis de la ciudad de Murcia hacia mediados del siglo XIII, con la ubicación de los principales establecimientos y de la excavación de la calle Pascual, incluida entre los alfares.

islámica en el periodo reseñado, así como la relación de la misma con las producciones de otros puntos de al-Andalus. Aparte de estos propósitos de carácter propiamente ceramológico, también pretendemos, mediante el análisis de estas producciones, intentar obtener alguna información de carácter esencialmente histórico, como la relativa a la cronología y características de la Murcia fundacional, y al papel que desempeñó como capital provincial del Estado cordobés en el proceso de arabización e islamización del sureste peninsular.

Será necesario establecer, de la manera más precisa posible, la cronología de los repertorios cerámicos identificados, para lo que contamos con diferentes fuentes de información que emplearemos de manera combinada. En primer lugar, la estratigrafía de la intervención de calle Pascual, que nos proporciona una cronología relativa fundamental para ordenar las series tipológicas según su relación deposicional. En segundo lugar, hemos seleccionado muestras de los niveles estudiados con el fin de llevar a cabo análisis arqueométricos, concretamente de $14 \mathrm{C}$ y sobre paleomagnetismo, en el marco de un proyecto de investigación en colaboración con Miriam Gómez-Paccard (et al., 2016).
En tercer lugar, las comparaciones formales entre los materiales que vamos a estudiar y otros del resto de al-Andalus que ya han sido publicados y datados de manera más o menos fiable. Conviene insistir en que vamos a tratar de un periodo oscuro desde el punto de vista historiográfico, por lo que esta información es mucho más escasa de lo que sería deseable; por otra parte, precisamente este desconocimiento justifica el interés del estudio que vamos a emprender. Acudiremos también a las publicaciones de los informes de otras excavaciones efectuadas en la ciudad de Murcia, en donde se encuentran algunas cerámicas de este momento no siempre bien identificadas. Finalmente, hemos revisado los materiales de un sondeo estratigráfico llevado a cabo en 1995 durante la intervención arqueológica realizada en el solar del edificio municipal del arquitecto R. Moneo en la plaza de Belluga, en el que se consiguió profundizar más allá de los -6'50 m, con el objetivo de documentar los niveles de ocupación más antiguos de la ciudad de Murcia.

Hasta la fecha no se habían publicado, o no se habían identificado en esta ciudad, conjuntos de materiales que se pudieran remontar al siglo IX. Incluso para época califal 
sólo contamos con dos contextos publicados con información relevante: el alfar de San Nicolás (NAVARRO, 1990) y el palacio de la calle Fuensanta (BERNABÉ y LÓPEZ, 1993); así como algún otro conjunto menor. Todos ellos, no obstante, son de gran valor para comparar y contextualizar adecuadamente la cerámica hallada en la calle Pascual.

Entre todos estos cabe destacar indudablemente el alfar de S. Nicolás, debido al amplio repertorio de piezas que permitió a Julio Navarro elaborar unas tablas tipológicas muy completas. No obstante, presenta también algunos problemas que ya pusieron de manifiesto Manuel Acién (1993: 169) y Sonia Gutiérrez (1996a: 348) y que impiden que lo acojamos como un referente indiscutible, al menos hasta que sea objeto de una revisión. Los materiales publicados forman parte mayoritariamente del testar del corte A-B, aunque las tablas están complementadas con piezas procedentes de otros vertederos hallados en el mismo solar. Todos ellos se sitúan estratigráficamente bajo el suelo de construcción de la vivienda que amortiza el taller, con lo cual el límite ante quem es el mismo; sin embargo, no hay seguridad de que todos estos depósitos sean exactamente coetáneos. Ni siquiera es posible afirmar, a juzgar por la estratigrafía, que los materiales del testar A-B sean exactamente del mismo momento, como ya advirtió Julio Navarro ${ }^{2}$.

Además de estos problemas estratigráficos relativos a S. Nicolás, tanto éste como el resto de los hallazgos murcianos que podríamos atribuir a esta época presentan la importante limitación de carecer de datos precisos acerca de su cronología. Por ello, para el estudio de conjuntos como el que vamos a abordar, es necesario acudir a las comparaciones tipológicas con los materiales procedentes de excavaciones añejas como las de Madinat Ilbīra y Madīnat al-Zahrā', efectuadas a fines del siglo XIX y durante la primera mitad del XX respectivamente; pues proceden de contextos que parecen bien documentados en las fuentes escritas. Desde entonces se han excavado otros importantes conjuntos de este periodo, como el ribāt de Guardamar (Alicante), Pechina (Almería), Cercadilla (Córdoba), Marroquíes Bajos (Jaén), etc., que también emplearemos como fuente de información, siempre con las precauciones que cualquier cotejo tipológico impone.

Las cerámicas de Ilbīra y al-Zahrā' se deben fechar en el momento de abandono y destrucción de ambas ciudades, que tuvo lugar en ambos casos a comienzos del siglo XI con motivo de la caída del califato. Se ha dicho que las piezas en verde y manganeso de Madīnat al-Zahrā' fueron desechadas antes de la destrucción de la ciudad palatina, debido a una "Oscura razón" (ESCUDERO, 1988-1990: 136), sin embargo nosotros entendemos que representan fundamentalmente el ajuar que estaba en uso en el momento de abandono de la ciudad palatina (1010), toda vez que muchas de las piezas se recuperaron dentro del alcantarillado, por lo que suponemos que se arrojaron cuando esta instalación dejó de funcionar. Un caso parecido debió de suceder en Madinat Ilbìra, dado que el conocido ajuar que incluye los magníficos ejemplares de verde y manganeso, se halló en su mayoría en el llano donde se encontraba la ciudad, que fue abandonada en el 1009-1010 según Ibn al-Jatīb y 'Abd Allāh Ibn Zīrī, aunque sería definitivamente destruida por los castellanos en 1075-1076 (CARVAJAL, 2008: 253-266).

En Pechina se documentaron dos fases: la más antigua está compuesta por rellenos sobre los que se construyeron unas viviendas y la más reciente corresponde al abandono de dichas casas. La decadencia de Pechina debió de comenzar a partir de 955, año en que se fundó Almería, la nueva capital de la

2 Según este investigador: "el depósito de desechos del corte A-B no se formó en un solo momento, dado que pudimos observar la presencia de una estratigrafía inclinada sobre la que se efectuaron otras deposiciones que regularon la topografía antigua, y generaron una base horizontal sobre la que se excavó el horno. Hasta que no se haga el definitivo estudio del ingente material exhumado no podremos afirmar con seguridad la contemporaneidad de todo el depósito del testar" (NAVARRO, 1990: 34). 
cora, pero su abandono no sería inmediato. Según al-'Uḍ̂īi, a quien debemos otorgar todo el crédito que merece ser testigo directo de estos hechos: "Los habitantes de Pechina se trasladaron a Almería en el año 402/ 4 agosto 1011-22 julio 1012" y más adelante: "Al contar Almería con una población en aumento, Pechina se arruinó; los últimos restos de ella desaparecieron en el año 459/22 noviembre 1066-10 noviembre 1067”' (AL-“UDRĪ, 1975-6: 35 y 49). Por tanto, si admitimos que no es muy plausible que después del año 955 se construyeran casas en Pechina, podemos concluir que existe un alto grado de probabilidad de que los materiales de la fase más antigua sean anteriores a esa fecha, lo que significa que podrían ser emirales o, incluso, de comienzos del califato. En cuanto a las cerámicas de la segunda fase, según al-'Uḍī la decadencia de Pechina comenzó con la fundación de Almería en 955, por lo que podrían ser de la segunda mitad del siglo X, o incluso de mediados del XI dado que los últimos restos de ella desaparecieron en 1066, de acuerdo con el geógrafo de Dalías. No obstante, lo más probable es que daten del primer cuarto del siglo XI momento en que los habitantes de Pechina se trasladaron a Almería. Por consiguiente, las cerámicas de este nivel II serían prácticamente contemporáneas de las de los contextos de abandono de Madīnat al-Zahrā' y Madīnat Ilbīra.

Un contexto cronológico similar encontramos en el yacimiento del ribāt de Guardamar: un nivel bajo los pavimentos de los oratoriosy otro sobre estos correspondiente al abandono. A diferencia de Almería, aquí las fuentes literarias no proporcionan información alguna; lo que conocemos con precisión es la fecha de la construcción de los edificios en el año 944 gracias a la epigrafía conmemorativa. De acuerdo con la estratigrafía, el yacimiento se abandona de forma repentina y no por causas violentas, en un momento impreciso que se ha fechado, mediante la tipología de la cerámica del nivel reciente, a fines del siglo X y primer cuarto del XI (AZUAR, 1989a: 140; MENÉNDEZ,
2004: 130). En resumen, se han agrupado las series tipológicas en tres conjuntos desde el punto de vista cronológico: las piezas anteriores al año 944, las coetáneas al 944 y las claramente posteriores a ese año (MENÉNDEZ, 2004: 97).

En Cercadilla (Córdoba) se documentó una secuencia estratigráfica compleja, que incluye un sector ocupado en época emiral. De época califal data la urbanización de la zona, al construirse numerosas viviendas que formaban parte de un arrabal. Se debió de abandonar con motivo del clima de inseguridad que acompañó a la guerra civil cordobesa del año 1010 (FUERTES, 2002; id., 2010). No existen referencias cronológicas absolutas, aunque la comparación de los materiales de este último nivel con los de Madīnat al-Zahrā' y las referencias en las fuentes escritas permiten suponer que, efectivamente, estas producciones deben de datar de comienzos del siglo XI. Este mismo problema de ausencia de datos cronológicos precisos se da, finalmente, en Marroquíes Bajos (Jaén), por lo que las dataciones han tenido en cuenta las relaciones estratigráficas, también complejas como en Cercadilla, y los paralelos tipológicos (PÉREZ ALVARADO, 2003: 35-39).

En un futuro, además de la revisión de los materiales recuperados a lo largo de décadas en la ciudad de Murcia y las nuevas intervenciones que en ella se puedan acometer, otros yacimientos tudmiries podrán ofrecer información importante acerca de las producciones alfareras del siglo IX. Muchos de ellos son contextos de ambiente rural del bajo Segura, estudiados por Sonia Gutiérrez, que debieron de estar habitados a mediados del siglo IX y que pudieron abandonarse antes del siglo X, por lo que revisten especial interés (Cabezo Pardo, Cabezo de las Fuentes, Cabecicos Verdes, Cabezo del Molino, el Forat y también El Zambo en Novelda y Peña María en Lorca). Destacamos entre ellos el Cabezo Pardo ${ }^{3}$ y el Cabezo de las Fuentes, que consti-

3. Agradecemos a Victoria Amorós la información acerca de este yacimiento. 
tuyen un único lugar y han sido identificados con la alquería de Tell al-Jațtāb dada en dote por Teodomiro por el matrimonio de su hija con el yundí 'Abd al-Yabbār b. Nadìr, quien dará origen al linaje de los Banū Jațāāb (GUTIÉRREZ, 2014: 276). Inicialmente fueron estudiados los restos de superficie, datándose entre mediados del siglo VIII y finales del IX (GUTIÉRREZ, 1996a: 354-355; GUTIÉRREZ, MORET, ROUILLARD y SILLIÉRES, 1998-1999: 42-45), y a partir de 2005 se han realizado dos campañas de excavación en el primero de ellos (LÓPEZ y XIMÉNEZ, 2008). También hay que destacar otros enclaves de Tudmīr que pudieron abandonarse a consecuencia del fin de las revueltas contra Córdoba a fines del s. IX o comienzos del X, como el Cabezo de las Fuentes de Archivel (Caravaca) ${ }^{4}$ y también el despoblado y castillo de las Paleras de Alhama.

Antes de comenzar con el análisis de estas producciones cerámicas emirales de Murcia, es necesario recordar la importancia del contexto histórico en el que se sitúan, debido principalmente a dos razones:

- En primer lugar, por el argumento temporal. La fundación oficial de Murcia está bien atestiguada por las fuentes escritas en el año 825 (CARMONA GONZÁLEZ, 2014); sin embargo, hay también indicios en los que algunos investigadores se apoyan para suponer que existía ya una población anterior en el mismo solar. Por consiguiente, el estudio de los materiales hallados en los niveles antrópicos más profundos de las intervenciones efectuadas en Murcia puede servir para confirmar o desmentir esta hipótesis, arrojando luz sobre un debate secular. Desde el punto de vista estrictamente ceramológico también es muy importante poder despejar esta incógnita, puesto que, si efectivamente se confirma la creación de la ciudad ex novo en el año 825, contaremos con un límite cronológico preciso, una fecha absoluta, para poder datar los materiales recuperados en los niveles más antiguos, lo que constituye una gran ayuda a la hora de poder avanzar en la evolución de los repertorios cerámicos y su ubicación temporal.

- En segundo lugar, por el argumento geopolítico. La fundación de una ciudad como Murcia, creada por el Estado cordobés para el control político y fiscal de un territorio, poblada por gobernadores, tropas y personal vinculado directamente a la administración estatal, junto con los mercaderes y artesanos que acudirían ante las oportunidades comerciales que proporcionaba la nueva capital, significó el establecimiento de un punto fuerte en el proceso de islamización, cultural y, sobre todo, política y económica, de una región marginal y rebelde como era Tudmir. Es de esperar, por consiguiente, que el ajuar cerámico de los que poblaron el nuevo centro de poder fuera sensiblemente diferente del de las comunidades campesinas levantiscas de origen muladí o bereber que habitaban alquerías y husūn; e incluso del de los árabes baladíes y yundíes asentados desde antiguo, cuyos enfrentamientos armados parecen haber sido el detonante de la nueva fundación.

\section{La excavación de calle Pascual: estratigrafía}

En el solar pudimos documentar de manera exhaustiva la ocupación ininterrumpida de este espacio desde la Alta Edad Media hasta la actualidad. Los niveles antrópicos más antiguos se hallaban a unos $-5^{\prime} 25 \mathrm{~m}$ de profundidad; desgraciadamente no pudimos exhumarlos en extensión. Sobre ellos encontramos las trazas de un primer urbanismo emiral que comienza a parcelar el espacio de acuerdo con una disposición que pronto experimentó modificaciones internas, aunque ya aparecen medianeras que se mantendrán

4. Excavado bajo la dirección de Francisco Brotóns Yagüe. 
estables durante siglos. A finales del período emiral o inicios de época califal se configura una vivienda, que ocupa la mayor parte del solar, cuya organización general de los espacios -un patio central y crujías alrededor-, se mantendrá hasta el siglo XVIII. A partir de ese momento las casas se sobreponen repitiendo los mismos espacios, aunque rehaciendo muros y solerías.

Para este trabajo hemos escogido un sector determinado de esa casa medieval, el correspondiente a la crujía este, que es donde pudimos excavar a mayor profundidad y donde documentamos una secuencia estratigráfica más amplia.

La compleja sucesión de niveles entre los siglos IX y XI queda representada en un croquis estratigráfico (Fig. 2) en el que, tomando como base una sección acumulativa, se han unido los dibujos de perfiles. No se trata de un perfil real puesto que hemos desplazado la fosa califal con el fin de que en una sola sección aparecieran representados todos los estratos y sus relaciones. En el presente trabajo sólo estudiaremos las producciones cerámicas correspondientes a las fases I a V. Por orden de antigüedad, éstas son las que documentamos en el espacio en cuestión:

Fase I. Al vaciar y perfilar una fosa posterior (fase II) que alcanzaba $5.25 \mathrm{~m}$ de profundidad con respecto a la superficie actual, pudimos documentar una columna estratigráfica compuesta por casi $2 \mathrm{~m}$ de estratos arcillosos que contenían cerámicas, intercalados por pequeñas franjas de limos estériles (UUEE 2131-2137). Éstos son los niveles más antiguos desde el punto de vista deposicional, lo que también quedó demostrado al estudiar la cerámica. Lo que no pudimos determinar es el tipo de actividad asociada a ellos, aunque creemos que podría tratarse de vertederos.

Fase II. Los niveles anteriores fueron seccionados por unas fosas asociadas, creemos, a una actividad alfarera. Se trata de una gran fosa hemiesférica para acumulación de arcillas (UE 2129), que fueron parcialmente extraídas posteriormente mediante una excavación o barrera que dio lugar a un hoyo, a su vez colmatado con un sedimento (UE 2127) que proporcionó la cerámica que ahora estudiaremos.

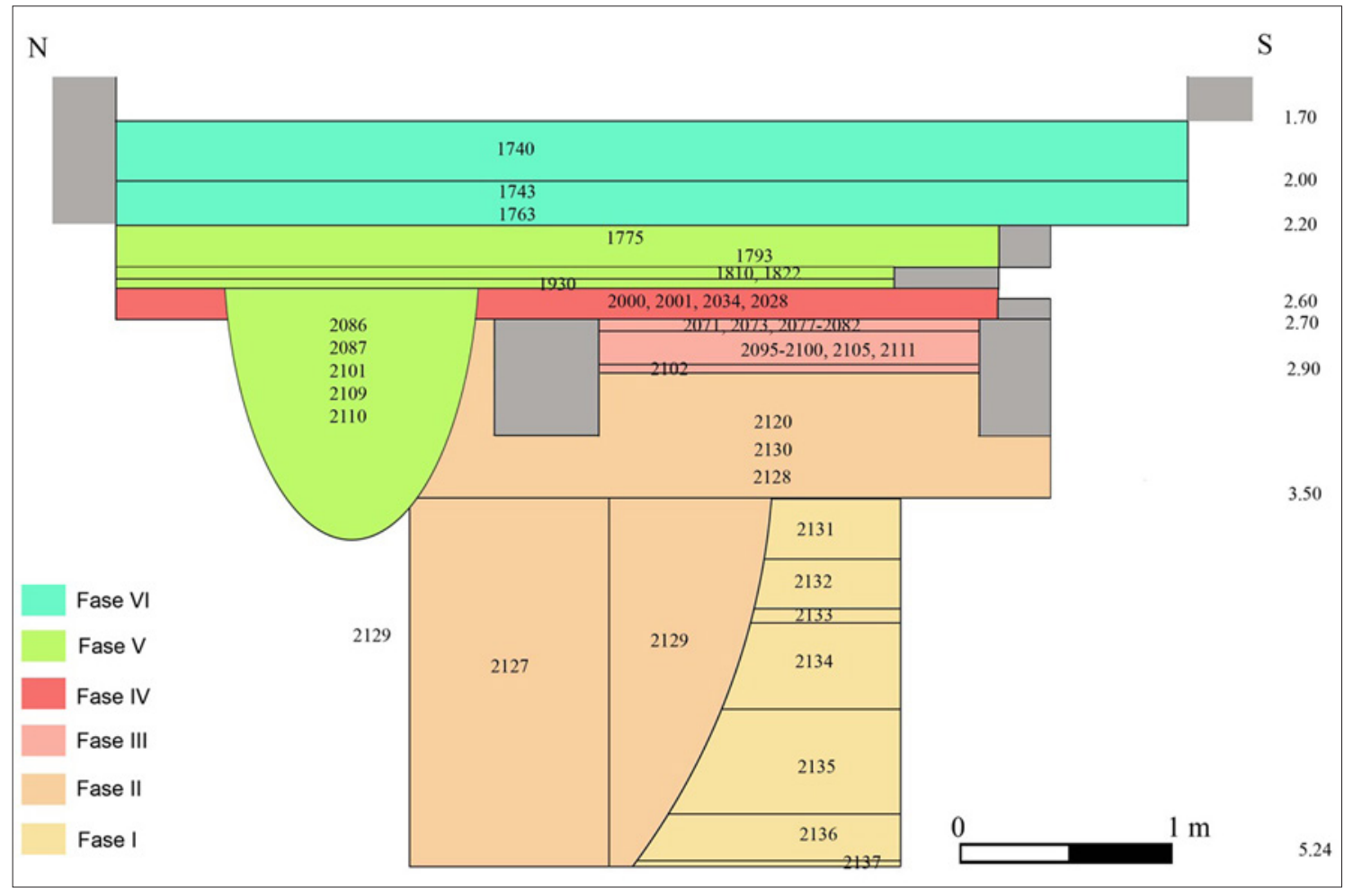

Fig. 2. Sección estratigráfica del sector estudiado de calle Pascual. 
Fase III. Sellando la actividad alfarera documentamos el extremo de una habitación rectangular, cuyo eje mayor tenía orientación este-oeste, donde se realizaron actividades de cocina. Numerosos tannures, hogares, cenizas, carbones, caracoles, cerámicas, etc., aparecen distribuidos en varias capas por toda la superficie conservada. Esta fase es susceptible de ser subdividida, tanto por la superposición de horizontes de ocupación como por las reformas en los muros.

IIla. Construcción de la cocina, uso y súbita destrucción que preservó piezas completas e in situ sobre el suelo (UUEE 2095-2100, 2102, 2105, 2111).

IIIb. Reconstrucción de la cocina, uso y posterior amortización (UUEE 2071, 2073, 2077-2082).

Fase IV. Sobre la cocina anterior se estableció otra, aunque ésta de orientación norte-sur, que ocupaba la crujía este de una vivienda de patio central construida en este momento y que mantendrá su organización general hasta el siglo XVIII (UUEE 2000, 2001, 2034, 2028). Los restos cerámicos asociados a esta fase son escasos.

Fase V. En este momento, que situamos en una fase final de la época califal, se reconstruye la vivienda y en la crujía en cuestión se edifica otra cocina, que en origen se abre completamente al patio por su frente occidental enmarcado únicamente por dos pilastras en los extremos, a modo de cenador. Éste es el último de los niveles que estudiaremos en el presente trabajo por razones de extensión de la publicación; los sucesivos quedan para nuestro siguiente estudio, aunque ahora resumiremos sus características para no dejar incompleta la secuencia general de época andalusí hasta el siglo XII. Se puede dividir en varios niveles:

- Va. Construcción de la cocina (UE 1930). A esta fase se asocia la colmatación de una fosa bajo el patio que rompía los niveles previos, con abundante material cerámico en buen estado de conservación, (UUEE 2086, 2087, 2101, 2109, 2110).
- Vb. Niveles de uso de la crujía (UUEE 1810, 1822)

- Vc. Nuevos horizontes de uso (UE 1793)

- Vd. Relleno sin materiales (UE 1775) de un momento de amortización que se puede asociar a la reconstrucción correspondiente a la siguiente fase.

Fase VI. Sobre la cocina anterior se construyó una estancia que se comunicaba con el patio a través de un vano geminado. Esta fase, que data ya de época taifa, se puede subdividir en dos horizontes puesto que sobre el suelo original se depositó un relleno y se repavimentó la pieza. Es posible que, al menos en el segundo de estos momentos, no estemos ya ante una cocina sino ante un salón, lo que sabemos con seguridad que sucedió en la fase siguiente.

Fase VII. Consiste en la construcción de una sólida casa con típicas técnicas constructivas del siglo XII. Sobre el espacio que estudiamos se construirá un nuevo salón. Por encima de este nivel existen otros momentos sucesivos que se prolongan en el tiempo hasta época moderna.

\section{La Fase I}

No pudimos excavar en extensión los niveles anteriores al alfar de la fase II y solo al perfilar la fosa generada por dicha actividad artesanal nos fue posible recuperar algunas cerámicas que son las que ahora presentamos (Fig. 3); por tanto, desconocemos el contexto de uso asociado a estos materiales. Este conjunto de cerámicas, el más antiguo de los hallados en este solar, corresponde a las UUEE 2134 y 2135 situadas a una profundidad de entre - 4 y - 5 m en relación a la cota actual de la calle. No podemos decir mucho desde el punto de vista tipológico dado lo fragmentario y escaso del material recuperado, apenas 25 fragmentos de la UE 2135 y solo 6 de la 2134, pero sí podemos afirmar que es islámico, y no hablamos sólo de cronología sino de los rasgos de las formas identificadas y sus características técnicas. 


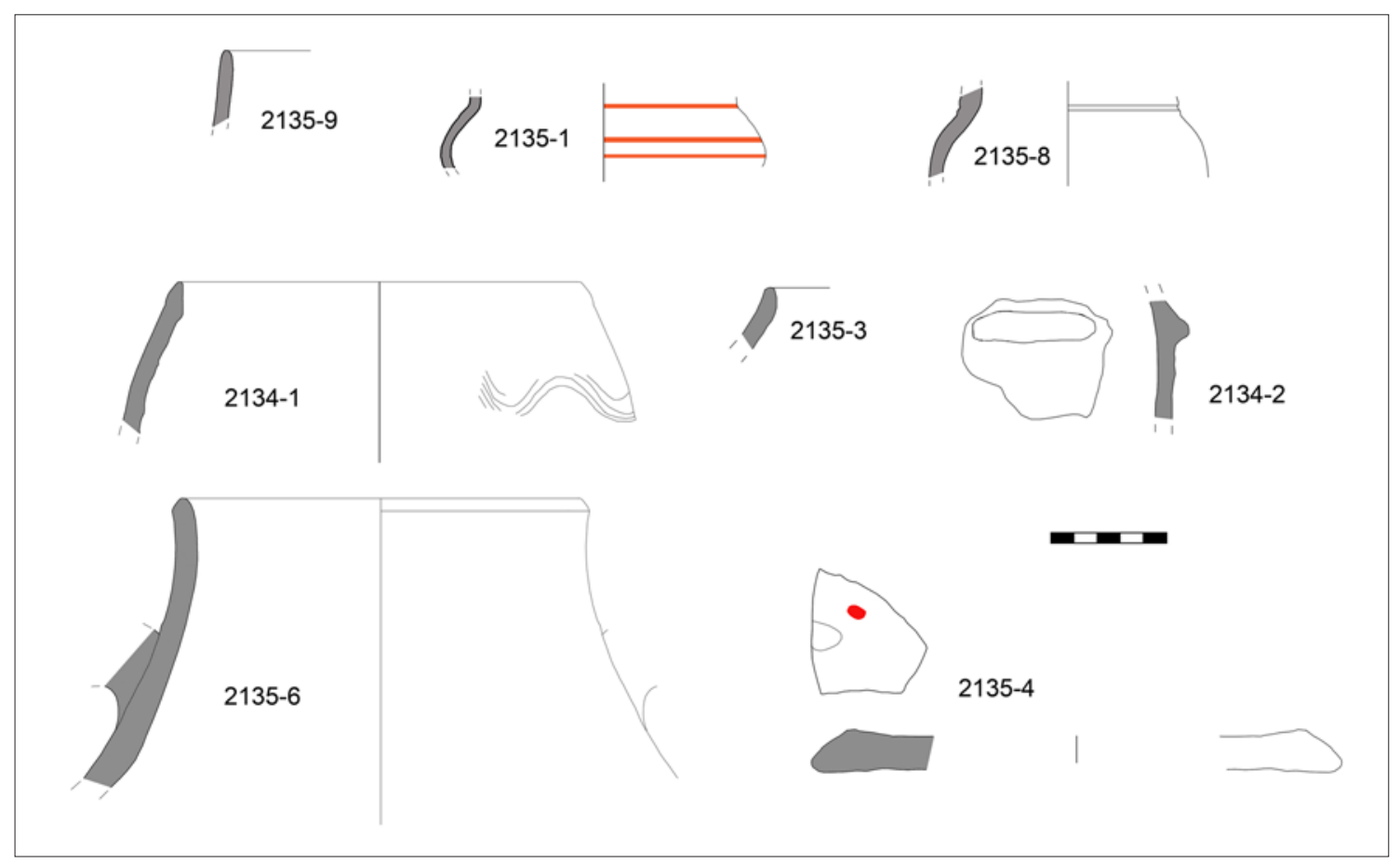

Fig. 3. Cerámica de la Fase I.

No hay formas de mesa abiertas, pero abundan las cerradas de pequeño tamaño: 11 fragmentos de los típicos jarros de boca ancha realizados a torno, un 35,48\% de los fragmentos recuperados en estas UUEE. Casi todos presentan unas pastas de tonalidades pajizas o rosáceas y aspecto poroso (2135-1, 2135-8 y 2135-9). Algunos de estos fragmentos muestran en el galbo decoración pintada a pincel consistente en finas líneas rojas horizontales o filetes. Es el caso de una pieza (2135-1), de la que se conserva el arranque de un cuerpo de perfil seguramente lenticular, que recuerda a otras que se documentan en contextos de la segunda mitad del siglo VIII y comienzos del IX ${ }^{5}$. El ajuar de cocina está representado únicamente por marmitas a mano de base plana y cuerpo más o menos troncocónico (6 fragmentos). De los dos fragmentos de borde con que contamos, el primero muestra una boca que tiende a cerrarse, rematando en un labio algo engrosado, además de decoración incisa a peine en bandas onduladas (2134-1); mientras que el borde del segundo se exvasa ligeramente a partir de un hombro entrante (2135-3), muy similar al de la pieza anterior. Otra marmita, de la que conservamos solo un fragmento de la parte superior, presenta un mamelón en forma de lengüeta (2134-2). En relación también con la actividad de cocina, según creemos, se halló un fragmento de tapadera plana que muestra digitaciones incisas sobre el borde y escasos restos de almagra (2135-4). Las vasijas de almacenaje (10 fragmentos), de tamaño considerable, están realizadas a mano; es el caso de una gran jarra o tinaja de la que solo conservamos el borde (2135-6).

Los datos intrínsecamente cerámicos para la datación de esta fase son muy escasos aunque, en general, podemos decir que se trata de formas plenamente islámicas, sin las pervivencias visigodas que suelen ser habituales para el siglo VIII (ALBA y GUTIÉRREZ, 2008). Aunque aún carecemos de suficiente

\footnotetext{
5. Por ejemplo, el 60825-24 y el 61375-27 del Tolmo de Minateda, ambos de la fase 2 y no representados en la 3 (AMORÓS, 2011: 115, 145, 161 y 175, figs. 66, 96, 114 y 137). En Šaqunda una jarra (2.1.1.2) parece tener características similares (CASAL, CASTRO, LÓPEZ y SALINAS, 2005: fig. 6).
} 
información respecto a la cerámica del siglo VIII y primera mitad del IX, todo parece indicar que, partiendo de un ajuar de tradición visigoda, paulatinamente se produjo la introducción de nuevos tipos (jarritas/os de boca ancha, tannures, candiles, etc.) de acuerdo con un proceso que se viene relacionando con el de islamización de la población. Al mismo tiempo las antiguas formas van desapareciendo o evolucionando en otras que serán las típicas de época paleoandalusí y que, en algunos casos, perdurarán más allá, perfectamente integradas en el ajuar andalusí pleno. Este proceso continuará al menos durante parte del siglo IX.

Veamos algunos ejemplos. En el Horizonte II del Tolmo de Minateda, datado entre la segunda mitad del siglo VIII y comienzos del IX, gran parte del material recuerda al de época visigoda; a este sustrato se irán agregando gradualmente las técnicas y formas características de las cerámicas islámicas (AMORÓS, 2011: 72, 177-178; GUTIÉRREZ, GAMO y AMORÓS, 2003: 142 y 148). En términos similares se ha señalado para el mismo yacimiento que lo visigodo se mantiene hasta finales del siglo VIII, mientras que la cerámica islámica predominará solo a partir del cambio de centuria (CAÑAVATE, MELLADO y SARABIA, 2009: 22). En Marroquíes Bajos (Jaén), la secuencia medieval se inicia en un contexto de características visigodas, cuya paulatina sustitución por otro repertorio se interpreta como el reflejo material del largo proceso de implantación de la sociedad islámica (PÉREZ, MONTILLA, SALVATIERRA y CASTILLO, 2003: 396, 407 y 408; PÉREZ, 2003: 28 y 29). A comienzos del siglo IX el ajuar de Šaqunda presenta formas plenamente islámicas, pero sus "características formales y decorativas recuerdan en algunas ocasiones a momentos cronológicos previos, periodo preemiral (s. VII-s. VIII)" (CASAL, CASTRO, LÓPEZ y SALINAS, 2005: 212). Igualmente, en Mérida "se puede encontrar un hilo conductor desde el siglo VI hasta el IX y no podemos hablar de total ruptura entre el mundo visigodo y el islámico, sino más bien de los caminos divergentes que siguen la cerámica común y la de lujo que afectan a las dos vertientes por separado" (ALBA y FEIJOO, 2003: 492).
La ausencia de fragmentos vidriados en la Fase I de calle Pascual es una muestra de la antigüedad relativa del ajuar analizado. Según Gutiérrez en el siglo IX aparecerían los "primeros vidriados monocromos decorados bajo cubierta" (2007: 306); en concreto, a mediados de siglo se daría la producción de ejemplares con cubiertas vitreas eminentemente funcionales en alfares urbanos del sureste (Pechina y Málaga) (GUTIÉRREZ, 2011: 203). Las excavaciones del arrabal de Šaqunda, fundado a mediados del siglo VIII y arrasado en el año 818, han mostrado la completa ausencia de vidriado (CASAL, CASTRO, LÓPEZ y SALINAS, 2005: 193). Igualmente, en Córdoba se halló un pozo negro bajo la mezquita mayor, fechado entre 756-786, que contenía 16 piezas casi completas, ninguna de ellas vidriada (FERNÁNDEZ-PUERTAS, 2009: 77-84). De la misma manera, en Cártama (Málaga) se asocian dos vertederos sin vedrío a la primera mitad del siglo IX (MELERO, 2009: 34). Sin embargo, según Victoria Amorós en el Tolmo de Minateda aparece el vidriado islámico, en escasas proporciones, a finales del siglo VIII (2011: 189-190). En Volúbilis (Marruecos), la ocupación idrisí de finales del siglo VIII que se extendió hasta algún momento del IX, deparó el hallazgo de un fragmento de jarro vidriado en una fase que podría ser de mediados de este siglo (FENTRESS y LIMANE, 2010: 113-114; AMORÓS y FILI, 2011: 36-37, 43 y fig. 23.4). En Marroquíes Bajos (Jaén), el vidriado, aunque presente desde antes, solo comienza a ser significativo en el último tercio del siglo IX (PÉREZ, MONTILLA, SALVATIERRA y CASTILLO, 2003; 395). Una pieza cerrada hallada en la provincia de Sevilla que contenía 169 dirhems datados en el intervalo 775-872, presentaba cubierta vítrea melada y decoración de líneas verdes (CANTO y RETUERCE, 1993). De todo lo cual cabe concluir que el vedrío islámico para el período anterior a mediados del siglo IX, es excepcional o inexistente.

En el conjunto de calle Pascual es significativa la presencia de jarros de boca ancha, característica forma que a partir del siglo VIII aparece en los ajuares andalusíes conviviendo con otras de tradición visigoda y que, según S. Gutiérrez, constituye uno de los mejores indicadores cronológicos y materiales del 
proceso de islamización (GUTIÉRREZ, 2007: 307 y 308; ALBA y GUTIÉRREZ, 2008: 602). Por ejemplo, en el Tolmo de Minateda será en la segunda mitad del siglo VIII, en las últimas fases del Horizonte II, cuando se documente (AMORÓS, 2011: 83, 149, 178, 183). En el arrabal de Šaqunda de Córdoba (750-818) su equivalente parece contar con dos asas y se asocia mayoritariamente a pastas claras que ya están bien representadas entre la segunda mitad del VIII y comienzos del IX (CASAL, CASTRO, LÓPEZ y SALINAS, 2005: 197-198, 209). En el pozo bajo la mezquita de Córdoba, del tercer cuarto del siglo VIII, no están presentes los jarros que tratamos, aunque sí otras variantes formales (FERNÁNDEZ-PUERTAS, 2009: 77-84). En Jaén los jarros de boca ancha se documentan a mediados del siglo IX (PÉREZ, MONTILLA, SALVATIERRA y CASTILLO, 2003: 403, 407 y fig. 9). La decoración pintada que ofrecen estas piezas de la calle Pascual es típica de la época emiral en el sureste desde fases tempranas (GUTIÉRREZ, 1996a: 160-162; ALBA y GUTIÉRREZ, 2008: 589).

En principio, la cerámica de cocina no podría datarse antes de finales del siglo IX si fuese cierto lo que se ha venido afirmando acerca de la decoración incisa a peine (GUTIÉRREZ, 1996a: 76-79). No obstante, creemos que esta cuestión debe ser objeto de revisión, puesto que tanto en calle Pascual como en Cardenal Belluga, las dos secuencias estratigráficas de la ciudad de Murcia que hemos podido revisar, las marmitas así decoradas están presentes en niveles que claramente se deben fechar en el siglo IX teniendo en cuenta la estratigrafía y el resto del ajuar que las acompaña.

En resumen, no hay duda de que el contexto cerámico descrito se debe fechar al menos en el siglo IX pero, además, la secuencia estratigrafía posterior a los niveles estudiados y que aún debemos fechar en época emiral, nos indica que debemos optar por una cronología temprana. Por consiguiente, teniendo en cuenta la información que proporcionan la comparación de las cerámicas con otros yacimientos y la coincidencia de las fuentes escritas en que Murcia se fundó en el año
825 , creemos que esta fecha puede servir como límite post quem La estratigrafía apoya esta hipótesis, puesto que el estrato se sitúa directamente por encima de un nivel de arcilla de origen natural, sin huellas antrópicas (UE 2136). La datación ante quem es difícil dada la escasez de materiales e incluso la poca información arqueológica acerca de la naturaleza de estos niveles, pero todo apunta a que no llega al último cuarto del siglo IX. Por consiguiente, esta fase la dataríamos entre el año 825 y el 875; no obstante, esperamos que futuras intervenciones en la ciudad, o la revisión de alguna de las ya efectuadas, puedan aportar datos que permitan confirmar, ajustar o corregir esta horquilla cronológica.

\section{Fase II}

En el nivel de alfar (Figs. 4 y 5) son muy abundantes las formas cerradas de mesa, jarritos y/o jarros: 74 fragmentos sobre un total de 215 , es decir, un $34,41 \%$, proporciones similares a las del nivel anterior (Fig. 4, 2127-4, 2127-5, 2127-6, 2127-10, 2127-11, 2127-32), que destacan por estar fabricados a torno y tener pastas blanquecinas o rosáceas de aspecto poroso, algunos de ellos con barros muy depurados. Suelen presentar la típica decoración de época emiral consistente en finas líneas horizontales rojas pintadas sobre la parte superior del cuerpo y en el cuello (GUTIÉRREZ, 1996a: 160-162; ALBA y GUTIÉRREZ, 2008: 589), que ya habíamos visto en la fase anterior. Por el contrario, aún no documentamos con claridad las digitaciones a la almagra, lo que conviene con lo observado en los contextos de la Plaza del Cardenal Belluga coetáneos del que nos ocupa, que parecen mostrar que esta decoración se dará casi únicamente sobre las grandes jarras fabricadas a mano hasta bien entrado el siglo $X$.

Aunque la mayoría de esos jarros presentan galbos curvos, hay un tipo de menor capacidad y cuerpo cilíndrico, representado por dos piezas de forma casi idéntica aunque de tamaño desigual (Fig. 4, 2127-4 y 2127-5). Partiendo de la base, el perfil presenta una inflexión previa al desarrollo de un galbo 


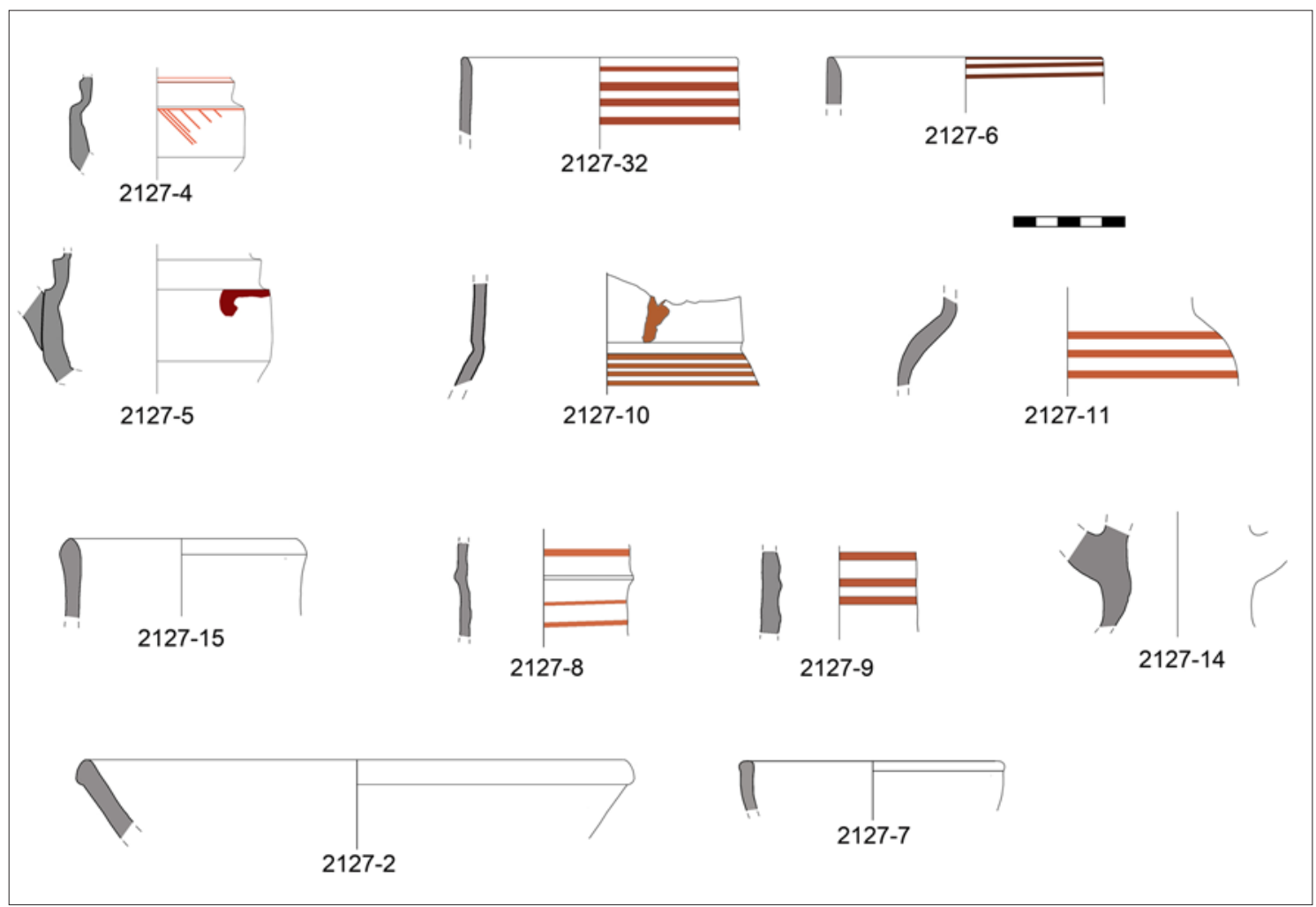

Fig. 4. Cerámica de la Fase II. Formas de servicio y almacenamiento.

recto y relativamente corto que remata en un profundo estrangulamiento en la unión con el cuello, favorecido por la existencia de una acanaladura; ambas piezas están fragmentadas por el cuello a la altura de otra acanaladura. No conocemos jarritos con este perfil en el siglo VIII, pero la tendencia del cuerpo cilíndrico entre marcadas inflexiones presenta similitudes con algunas producciones del siglo IX e incluso del X (GUTIÉRREZ, 1996a: 129133, formas V20.2 y V22). La decoración que presenta uno de estos jarritos (Fig. 4, 2127-4), aunque parcialmente perdida, remite a los triángulos de líneas oblicuas de época emiral (GUTIÉRREZ, 1996a: 160-162). Estos jarros los seguimos identificando en niveles de época califal temprana en calle Pascual así como en la plaza de Belluga, de manera que incluso da la impresión de que podríamos estar ante un fósil director del siglo IX y primera mitad del $X$, al menos en Murcia. Los pequeños jarritos carenados suelen documentarse casi siempre vidriados o se considera que estaban "preparados para ello" en contextos de la segunda mitad del siglo IX y comienzos del siglo $X$
(ACIÉN y MARTÍNEZ, 1989: 128-130 y fig. 3; CASTILLO y MARTÍNEZ, 1991: 67-68 y fig. VII; id., 1993: 88 y lám. VI; MOTOS, 1993: 229-231 y fig. 10; ACIÉN, CASTAÑO, NAVARRO, SALADO y VERA, 2003: 420, 422, 424, 426 y figs. 7 y 9; SALINAS, 2013: 70, 83 y fig. 9). Las formas sin vidriar suelen ser más sencillas, aunque en la ciudad de Málaga se han hallado piezas emirales con marcadas inflexiones y tramos troncocónicos, similares a las nuestras (î̃NlGUEZ y MAYORGA, 1993: 128-130 y lám. 6); y en Melilla se identificaron jarritos de cuerpo cilíndrico sin vidriar de finales del siglo IX O comienzos del $X$, uno de los cuales se asemeja parcialmente a los nuestros (SALADO, NAVARRO y SUÁREZ, 2011: 77 y fig. 13.52). En Murcia se han documentado, vidriados o desechados tras la primera cochura, en el alfar de San Nicolás (NAVARRO, 1990: 39) (Fig. 16, 12-13), lo que demostraría, de comprobarse su cronología califal, una perduración que también se ha registrado en la calle Pascual, en este caso sin que la estratigrafía ni los materiales asociados permitan albergar dudas sobre su datación. En la misma Murcia se atribuyó al 
siglo $X$ un conjunto hallado hace tiempo en la calle San Pedro, con piezas que parecen ser similares a las nuestras y sin vidriar, que a juzgar por la foto publicada y la descripción de las estructuras asociadas podría datarse en época emiral (GALLEGO y RAMÍREZ, 1993: 384 y 386). También en la secuencia de plaza Belluga pudimos comprobar que estas piezas son habituales en todos los contextos del IX hasta al menos la primera mitad del $\mathrm{X}$.

Otro jarro (Fig. 4, 2127-10), de mayor tamaño, presenta también una marcada unión de cuello y galbo que da lugar a un hombro troncocónico que parece preceder a una inflexión o incluso carena previa a la parte central del cuerpo. Este tipo se documenta ampliamente en el sureste en época emiral: Gutiérrez los sistematizó para Tudmīr en las formas T20.1, T20.2 o T20.3, fechándolos en la segunda mitad del VIII y siglo IX. Están muy bien representadas en El Zambo (GUTIÉRREZ, 1996a: 113, 114, 181 y figs. 79, 83); mientras que en el Tolmo aparecen estas piezas en el horizonte IIIb, datado a mediados del siglo IX, incluso una se considera producción de un horno de ese momento (GUTIÉRREZ, GAMO y AMORÓS, 2003: 137, 150-156 y figs. 11.4., 20.5, 21.3, 21.6, 23.3). Aquí los jarros son, en la segunda mitad del siglo VIII, mayoritariamente de tradición visigoda, introduciéndose paulatinamente el jarro de boca ancha (AMORÓS, 2011: 183), pues de hecho los primeros, que a partir de la segunda mitad del siglo VIII se elaborarán con las pastas finas y claras típicas de las producciones islámicas, continuarán siendo representativos a lo largo del siglo IX junto a los de boca ancha (AMORÓS, 2011: 144, 145 y 183). Sin embargo, en nuestro caso todos entrarían dentro de esta última categoría. También en un contexto del siglo IX de Lorca están presentes los jarritos/as con marcadas inflexiones en la zona de unión del cuello y el galbo (MARTÍNEZ RODRÍGUEZ y PONCE GARCÍA, 1995b: 309 y fig. 10). A este tipo parece responder también un jarro decorado con filetes rojos horizontales, hallado recientemente en Las Paleras de Alhama, un despoblado abandonado a fines de la época emiral ${ }^{6}$. Finalmente, ejemplares cuyos perfiles responden a esta misma tendencia están presentes en el nivel bajo pavimentos del ribāt de Guardamar que antes discutíamos (AZUAR, 1989a: 52 y 118; GUTIÉRREZ, 2004: 85).

Otros jarros, también fabricados a torno, presentan cuellos muy estrechos y rectos y decoración de filetes horizontales pintados en rojo (Fig. 4, 2127-8 y 2127-9). Finalmente, un jarro de cuello estrecho (Fig. 4, 2127-14) podría recordar a las botellas visigodas, aunque la pasta presenta las características propias de las producciones de época islámica. No sabemos exactamente cómo sería la forma completa de este recipiente, aunque podría tratarse del tipo de jarro de boca lobulada que suele presentar el cuello moldurado, como uno de nuestros fragmentos, o incluso de grandes redomas, series T16y T17 de Gutiérrez (1996a: 108-111).

Una de las novedades de este contexto con respecto al anterior es la aparición de formas abiertas de servicio, hecho que consideramos relevante a pesar de su escasísimo número. En concreto identificamos dos bordes, uno de un ataifor (Fig. 4, 2127-2) y otro de un cuenco o una jofaina (Fig. 4, 2127-7), ambos con el borde ligeramente engrosado al exterior y sin ningún tipo de tratamiento conservado -no están vidriados-, pero son de pastas claras y muy depuradas. Aunque no son habituales los ataifores en época emiral temprana, sí se registran abundantes cuencos, como se ha podido comprobar en contextos cordobeses de la segunda mitad del siglo VIII y primer cuarto del IX (CASAL, CASTRO, LÓPEZ y SALINAS, 2005: 189-235, 202, 224 y fig. 12). En el sureste e incluso en otros lugares como Mallorca e llbīra, la aparición de estos tipos, especialmente en contextos rurales, se suele asociar a momentos relativamente avanzados. Sin embargo, en las ciudades como Córdoba, Pechina y Málaga es frecuente la presencia de ataifores

\footnotetext{
6. Agradecemos a José Baños Serrano, directos del Museo de Alhama de Murcia, las fotos de estas piezas y la información acerca de la datación del yacimiento.
} 
y jofainas, incluso ya vidriados, desde antes de los últimos años del siglo IX. Tal vez pueda ser significativa la presencia temprana de estas piezas precisamente en ciudades en las que estaba firmemente asentado el Estado omeya, al igual que debía de suceder en Murcia, lo que implicaría un grado mayor de islamización y de arabización cultural. De esa manera se justifica el hallazgo en calle Pascual de formas abiertas de mesa sin cubierta vítrea en el siglo IX. En este sentido apuntan también las fases siguientes de la calle Pascual, aunque creemos más prudente aseverarlo cuando así lo corroboren otros conjuntos, teniendo en cuenta lo reducido de la muestra con que trabajamos.

Se conserva otro borde de un recipiente abierto de mayores dimensiones, pero la tosquedad de su manufactura a mano, junto con una pasta con grandes inclusiones (Fig. 5, 2127$3)$, nos hace pensar que no era un recipiente propiamente de mesa sino de uso múltiple.
Un borde engrosado al exterior parece pertenecer a una jarra de almacenaje que, aunque fabricada a mano (Fig. 4, 2127-15), se puede relacionar con la forma T11.1.1 de Gutiérrez, que ya se documenta plenamente en el Tolmo en la segunda mitad del siglo VIII y principios del IX (GUTIÉRREZ, GAMO y AMORÓS, 2003: 119-168, 144, 146-147, figs. 16.10 y 17.6; AMORÓS, 2011: 75, 83, 93, 116, 145, 151, 175 , 188, figs. 24, 32, 42, 67, 96, 105, 137, 146). También hay recipientes de almacenaje mayores (jarras y tinajas) que suelen estar hechos a mano, pero de los que solo conservamos fragmentos del galbo.

El ajuar de cocina consiste casi exclusivamente en marmitas fabricadas a mano y con decoración incisa a peine formando una banda horizontal ondulada (64 fragmentos). Son muy parecidas a las de la fase anterior, aunque en las que ahora nos ocupan el perfil se va cerrando más hacia la boca (Fig. 5, 2127-

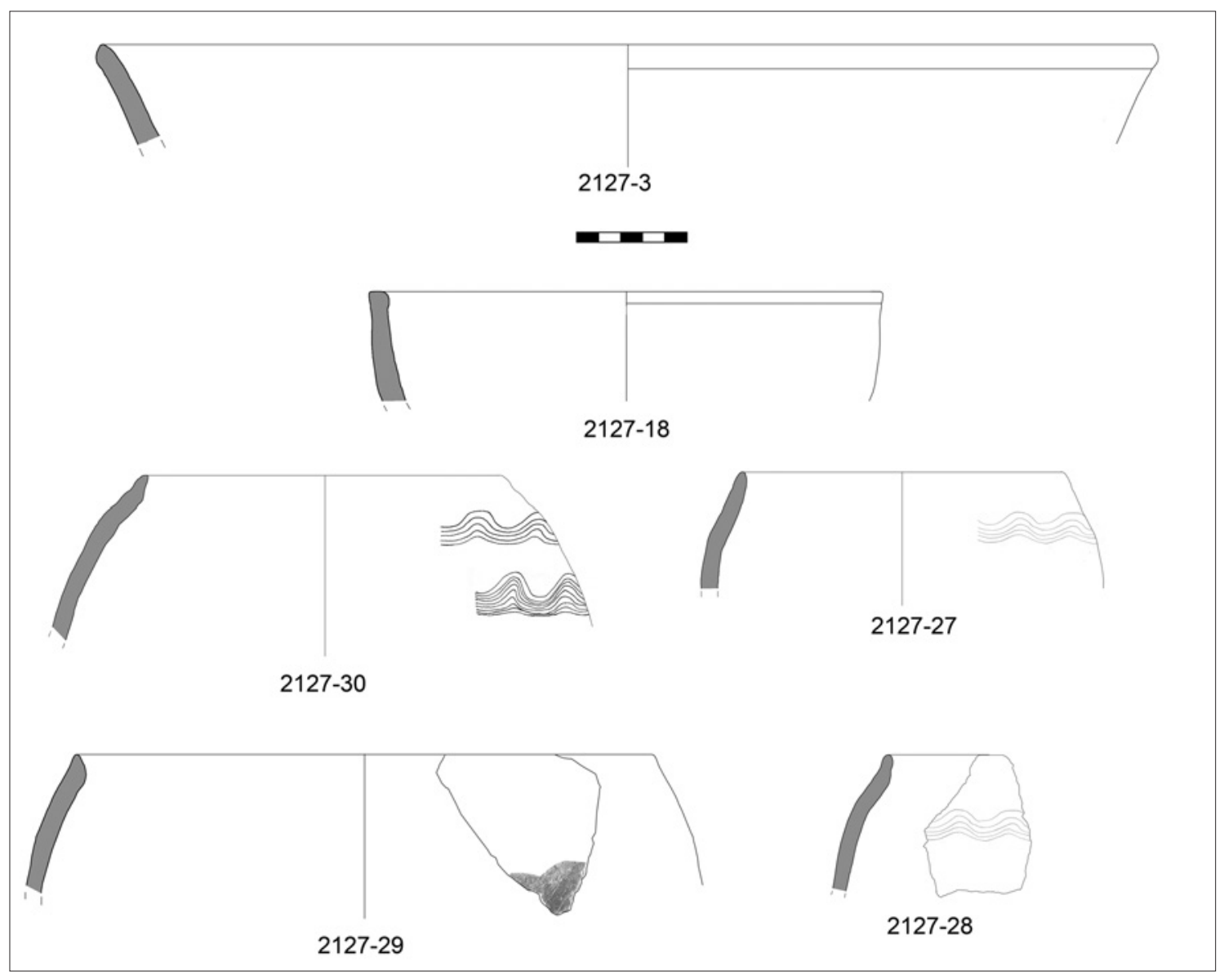

Fig. 5. Cerámica de la Fase II. Formas de cocina y usos múltiples. 
27, 2127-28 y 2127-30). Hallamos varios fragmentos de bordes, pero no tenemos ningún perfil completo. En cuanto a las cazuelas solo identificamos una (Fig. 5, 2127-18), fabricada a mano. Presenta una pasta distinta al resto de piezas, más compacta, negra al interior y de superficies marrones, por lo que podría tratarse de una pieza importada. Al igual que en Murcia parece suceder en Cartagena, donde las "marmitas a torno" están escasamente representadas (MURCIA y GUILLERMO, 2003: 200); sin embargo, en Lorca para el siglo IX sí que abundan las marmitas de borde vuelto conviviendo con las de borde entrante (MARTÍNEZ RODRÍGUEZ y PONCE GARCÍA, 1995b: 300-303). Finalmente, cabe destacar la presencia de las marmitas de la serie M4.2, con decoración a peine, cuya aparición se viene datando a fines del siglo IX o comienzos del X (GUTIÉRREZ, 1996a: 76-79 y 156-157), aunque, como vimos, están presentes también en la fase anterior de esta secuencia, datada entre el 825 y el 875. En relación a esta forma Gutiérrez (1996a: 76-79; id., 2004, p. 80) diferenciaba un tipo para el siglo IX y otro que sería ya propio de finales de ese siglo o comienzos del siguiente, que se distinguirían básicamente por la ausencia o presencia respectivamente de decoración incisa a peine formando ondas (tipos M4.1 y M4.2). Según la información de calle Pascual, durante todo el siglo IX Murcia tan solo produce las consabidas marmitas M4.2, mientras que las pocas ollas que se salen de este registro son importadas ${ }^{7}$. Efectivamente se trataría de una producción de origen urbano que posiblemente no se extienda en el ámbito rural hasta finales del siglo IX, como supuso Gutiérrez, aunque la excavación de calle Pascual demostraría que la presencia de decoración incisa en las marmitas, al menos en Murcia, comenzaría en una fecha algo más antigua ${ }^{8}$. También los últimos estudios sobre la cerámica del Tolmo de Minateda muestran que esta marmita aparece ya desde el inicio de la secuencia andalusí, a mediados del siglo VIII, aunque su presencia no será importante hasta finales de siglo o comienzos del IX (AMORÓS, 2011: 149 y 181).

Otras formas reconocidas, aunque no representadas en las tablas por su estado fragmentario de conservación, son un tannur; una pared de tinaja con refuerzo digitado y una loseta con el borde alzado (alizar) que recuerda a las tegulae romanas, aunque fabricada toscamente con una pasta que contiene numerosas intrusiones de gran tamaño.

La mayoría de conjuntos cerámicos tardoemirales documentados en el sur de al-Andalus (segunda mitad del siglo IX-primer tercio del s. X) parecen poder subdividirse en dos etapas: la más antigua, caracterizada por la existencia de vidriado solo en formas cerradas, fundamentalmente jarritos; la más reciente, en la que se incorporan las formas abiertas de mesa, ataifores y jofainas. Sin embargo, a juzgar por la bibliografía no parece que esta división fuera clara y uniforme y observamos que hay enclaves en los que no aparecen los ataifores vidriados o son muy excepcionales hasta época califal; mientras que en otros están ampliamente documentados en contextos tardoemirales en los que aún no se dan técnicas tradicionalmente asociadas al período califal como el verde y manganeso.

Es significativo el caso de Córdoba, donde tradicionalmente no se contemplaba la existencia de vidriado emiral. Esta suposición parecía refrendada por las excavaciones del arrabal de Cercadilla, donde el vidriado se considera excepcional hasta bien entrado el siglo X; incluso en relación a las formas cerradas ya que las pocas que se documentan se suponen importaciones procedentes del sureste (FUERTES, 2010: 264). Sin embargo, esta hipótesis está siendo matizada por el

\footnotetext{
7. Aunque este taxativo dato pudiera matizarse, según observamos entre los materiales emirales de la plaza de Belluga, en este caso la proporción de ollas sigue siendo baja con respecto a las marmitas.

8. Las excavaciones realizadas a principios de los 90 bajo el palacio Llorca en Alicante aportaron niveles en los que aparecían marmitas así decoradas en contextos estratigráficos que se fecharon a mediados del s. IX (ROSSER, 1994: 115-120), aunque posteriormente se corrigiera llevándolo a finales de ese siglo o primera mitad del siguiente, sobre todo, precisamente, por la presencia de la decoración a peine sobre las marmitas (GUTIÉRREZ, 1996a: 351-352).
} 
reconocimiento de cerámicas vidriadas emirales procedentes de distintas excavaciones, así como por el descubrimiento de un pozo tardoemiral con abundante material vidriado y producciones, tanto formas abiertas como cerradas, que presentan cubiertas vítreas polícromas como antecedente del verde y manganeso califal (SALINAS, 2013). Los ajuares tardoemirales de otros núcleos muestran características similares al de Cercadilla: el vedrío es escaso y se da siempre sobre formas cerradas. En Madinat Ilbīra, por ejemplo, los ataifores vidriados, coexistiendo con otros que no lo están, no aparecerán hasta la primera mitad del siglo X (CARVAJAL, 2008: 225); al igual que sucede en el Castillón de Montefrío (Granada), en donde el vedrío se da sobre formas cerradas de mesa. En Melilla se documentan, desde finales del siglo IX a principios del $X$, ataifores y jarritos sin vidriar que conviven con candiles y redomas vidriados (SALADO, NAVARRO y SUÁREZ, 2011). En Mallorca, conquistada en el año 902, se halló un silo colmatado de cerámica con un nivel inferior, que se atribuye a la primera mitad del $\mathrm{X}$, en donde aún no hay vidriado ni en los ataifores, mientras que en el contexto superior, con una datación por $14 \mathrm{C}$ en torno al 940, ya existen los vidriados e incluso la decoración en verde y manganeso (RIERA, 1999: 178, 185 y fig. 5).

Por el contrario, en el nivel I de Pechina se documentó una amplia variedad de formas vidriadas, entre ellas los jarritos y ataifores e incluso recipientes de cocina. Este nivel se fecha a grandes rasgos en la segunda mitad del IX, quizás en el último cuarto, aunque los propios autores admiten la posibilidad de una datación anterior (ACIÉN, CASTILLO y MARTÍNEZ, 1990: 148 y 149; CASTILLO y MARTÍNEZ, 1993: 69 y 70; ACIÉN, 1993: 169 y 170). Las cerámicas de Málaga presentan características parecidas a las de Pechina, al menos a finales del emirato o quizás ya desde mediados del s. IX, con una amplia presencia de formas de mesa vidriadas, tanto cerradas como abiertas. Aunque se desconoce cuándo se inician estas producciones pues no se tiene información acerca de la cerámica del siglo VIII y primera mitad del IX, sí que parece posible afirmar que se generalizan a partir de comienzos de la segunda mitad del IX (IINNIGUEZ y MAYORGA, 1993; ACIÉN, CASTAÑO, NAVARRO, SALADO y VERA, 2003: 417-426 y 433; SUÁREZ, FERNÁNDEZ, NAVARRO, CISNEROS Y MAYORGA, 2003: 30; MELERO, 2009). En Jaén los ataifores vidriados aparecen a mediados del siglo IX (PÉREZ ALVARADO, 2003: 126) o en el último tercio de ese siglo (PÉREZ, MONTILLA, SALVATIERRA y CASTILLO, 2003: 395). También en Valencia el vidriado se documenta ya en el siglo IX, aunque escasamente y asociado a ataifores similares a los de Pechina, sin que se hayan encontrado los jarritos vidriados emirales del sureste (PASCUAL, RIBERA y ROSELLÓ, 2003: 108, 111 y 113).

En relación al territorio de Tudmìr, Sonia Gutiérrez identificó en el ámbito rural un repertorio cerámico del siglo IX en el que el vidriado era muy poco significativo pues se limitaba a algunos tipos de jarros, mientras que los ataifores estaban ausentes; esas piezas vidriadas se consideran "procedentes de núcleos urbanos que comienzan a estructurar sus mercados, como Murcia" y también Pechina (GUTIÉRREZ, 1996a: 178). La existencia de esta hipotética producción emiral murciana se basaba en la revisión por parte de Acién de algunos de los materiales del alfar de San Nicolás, publicados como califales, entre los que hay muchas piezas similares a las de los niveles emirales de Pechina (ACIÉN, 1993: 169). Otros yacimientos confirman que en Tudmîr durante el siglo IX el vedrío era escaso y se daba sobre formas cerradas; mientras que la aparición de ataifores vidriados fue tardía y generalmente asociada al verde y manganeso. Es el caso del Tolmo de Minateda, en cuyo registro cerámico de pleno siglo IX no hay ataifores, aunque sí abundantes cuencos; mientras que el vidriado se restringe a recipientes cerrados de mesa que son considerados, en la mayoría de los casos, importaciones de Pechina (AMORÓS, 2011: 183; GUTIÉRREZ, GAMO y AMORÓS, 2003: 135, 148, 153, 155, 156 y fig. 10). También en Cartagena el vidriado se limita a escasas formas cerradas y no hay ataifores hasta época califal, aunque se atribuye a época emiral un ataifor en verde y manganeso sobre amarillo quizás procedente de Raqqāda (MURCIA y GUILLERMO, 2003: 204- 
205, 207, 209-210, 212 y figs. 16.113, 19.138). En Lorca se excavó lo que se consideró una alquería del siglo IX, donde se documentaron 29 fragmentos de cerámica vidriada, todos correspondientes a formas cerradas de mesa a excepción de 3 fragmentos de candiles y otros 3 de una misma pieza abierta de mesa (MARTÍNEZ RODRÍGUEZ y PONCE GARCÍA, 1995b: 305). En el Castellar de Alcoy, la revisión de los materiales emirales y califales de la excavación de los años sesenta, permitió detectar un tipo de ataifor de paredes divergentes y base plana, sin vidriar y con decoraciones a la almagra, que ha sido encuadrado entre fines del IX y primera mitad del X (PÉREZ BOTí, 2014: 53-68, 57-58, 64-66, figs. 5, 9, 10). El nivel bajo los pavimentos del ribāt de Guardamar proporcionó candiles vidriados, pero no formas abiertas así acabadas (GUTIÉRREZ, 2004: 80 y 81).

El conjunto de calle Pascual no ha aportado piezas vidriadas, de lo que no se puede inferir taxativamente que en esta fase no hubiera cerámica vidriada en Murcia, más bien parece que esta ausencia viene determinada por la escasa proporción de este tratamiento durante el siglo IX junto con lo restringido de la muestra con que trabajamos. De hecho, en el estrato más antiguo de la secuencia documentada en plaza Belluga, muy similar en materiales a éste que nos ocupa, ya aparece un fragmento de forma cerrada de mesa vidriado, muy probablemente un jarrito.

En resumen, estamos ante un ajuar emiral posterior al 850, sobre todo teniendo en cuenta la existencia de la fase anterior, que podría quedar acotado en la segunda mitad del siglo IX a juzgar por sus propias características y por las de las fases siguientes que analizaremos a continuación. De un carbón de este sedimento se obtuvo una datación por 14C, que ofreció un arco cronológico entre mediados del siglo VII y los dos primeros tercios del VIII, fecha que no podemos asignar a la formación del depósito, sino al momento en que murió el árbol, lo que nos ofrece un límite post quem menos preciso que el que proporciona el análisis tipológico de la cerámica, según hemos visto.

\section{Fases III y IV}

Los primeros niveles domésticos en la secuencia estratigráfica del sector de calle Pascual que venimos examinando nos depararon un registro cerámico muy interesante, variado y con algunas piezas completas (Figs. 6-8). Como dijimos, comprende, al menos, dos cocinas superpuestas, fases III (la inferior) y IV (la superior); de aquélla procede la mayor parte de los restos hallados. Son 639 fragmentos en total, de los cuales 603 corresponden a la fase III, compuesta por las unidades estratigráficas 2102, 2095, 2082, 2071 y 2034. En general, estas cerámicas presentan rasgos del período emiral final junto a otros que se suelen asociar a lo califal, destacando la ausencia de decoración en verde y manganeso.

La novedad más importante con respecto a la fase anterior es la aparición del vidriado, que está representado en 19 de los fragmentos, cerca del $3 \%$. Es por lo general de color melado, aunque también marrón e incluso verde, color que sólo hallamos en las formas cerradas. En un solo caso detectamos decoración de manganeso, que se combina con fondo melado (Fig. 6, 2095-1).

Dos fragmentos de galbo pertenecientes a una misma pieza cerrada (Fig. 6, 2095-4), presentan una irregular cubierta vítrea verde oliva al interior y una pasta muy depurada y de tonalidad asalmonada, rasgos que la alejan del resto del registro cerámico andalusí de Murcia. Lo poco que se ha conservado de su perfil muestra una inflexión y un exterior estriado que la asemejan a la decoración "excisa de dientes de sierra" de una pieza emiral de Pechina, a algunos jarritos emirales de Málaga y a otra de Cartagena (íNNIGUEZ y MAYORGA, 1993: 129, lám. 6; CASTILLO y MARTÍNEZ, 1993: 92-93 y lám. IX.6; MURCIA y GUILLERMO, 2003: 207, 209 y fig. 19.137). También escapa a las características mayoritarias del conjunto un fragmento del cuello de una forma cerrada que, sobre una pasta también sumamente depurada y rosácea, presenta al exterior una línea incisa bajo vedrío verde oscuro, mientras que la cara interna está 


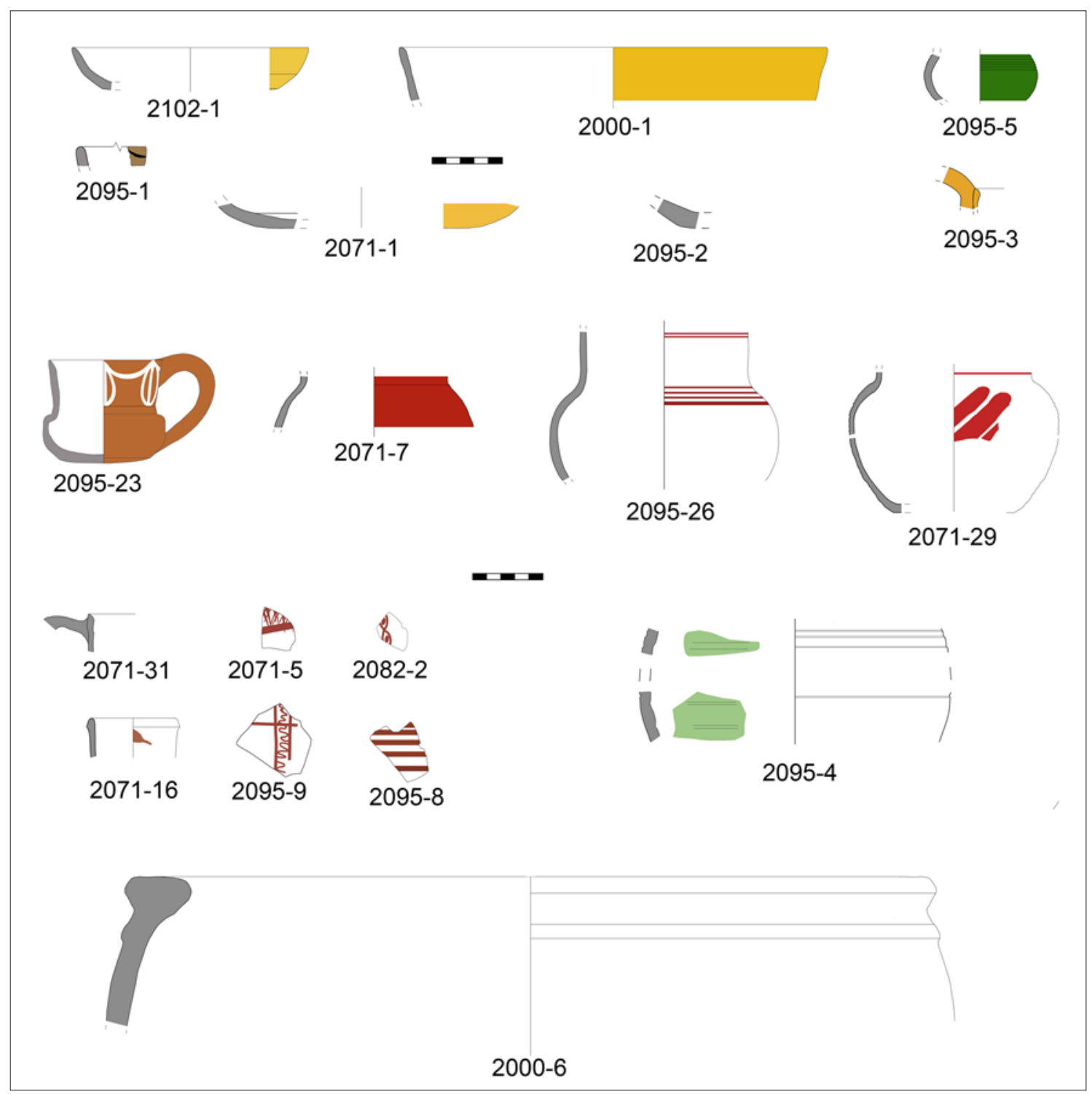

Fig. 6. Cerámica de las Fases III-IV. Formas de servicio y almacenaje.

degradada ${ }^{9}$. No podemos decir cuál es la procedencia de estas piezas, aunque sí podemos afirmar que no se trata de producciones murcianas.

Las formas abiertas de mesa están vidriadas y presentan formas sencillas, de base plana y paredes curvas bajas acabadas en bordes simples, rasgos generales que se dan en los ataifores emirales de Pechina, Málaga (ACIÉN et al. 1991: 126) y Córdoba (SALINAS, 2013, pp. 71, 83 y fig. 11), y en aquéllos vidria- dos de la Valencia emiral (PASCUAL, RIBERA, LACOMBA y ROSELLÓ, 2003: 11-113 y fig. 33) y Jaén (PÉREZ, MONTILLA, SALVATIERRA y CASTILLO, 2003: 404 y fig. 10).

En cuanto a los ataifores más antiguos, relacionados con la cocina inferior, tenemos una base plana con vedrío marrón oscuro al interior y melado moteado al exterior (Fig. 6, 2095-2); una jofaina de escasa altura y paredes exvasadas con vedrío melado en ambas caras (Fig. 6, 2102-1) y una base plana

9. Pieza no representada en dibujo. 
que presenta vidriado melado al exterior y al interior, bajo el vedrío degradado, una línea incisa concéntrica en la unión del fondo con la pared (Fig. 6, 2071-1). Las características tipológicas de estas piezas se asemejan bastante al tipo de ataifor emiral predominante en Pechina ${ }^{10}$, incluso en pequeños detalles, si bien no coinciden los colores de los vedríos ya que allí predominan el verde y el melado moteado (CASTILLO y MARTíNEZ, 1991: 66-67). La presencia en Murcia de un fragmento con una línea curva de manganeso combinada con vedrío melado también difiere de Pechina, pues allí esta bicromía solamente se encuentra en el nivel II, ya califal ${ }^{11}$.

Puede ser significativo que el único ataifor que hallamos en la cocina de la fase IV (Fig. 6, 2000-1), superpuesta a la que proporcionó los anteriores (fase III), sea más profundo que éstos, una diferencia que también se da entre los ataifores emirales y califales de Pechina (CASTILLO y MARTÍNEZ, 1993: 67). Sin embargo, los desechos de un alfar emiral de Málaga constituyen un conjunto donde coexisten ataifores de mayor profundidad, incluso con borde engrosado, junto a jofainas de perfil similar a las de Pechina, todo ello con diferentes vidriados, algunos bícromos en manganeso y melado o verde (ÍÑIGUEZ y MAYORGA, 1993: 123-126 y lám. 4). De hecho, no es extraño que en contextos de Málaga ciudad y su entorno, que se vienen fechando en el último cuarto del siglo IX, aparezcan ataifores de perfiles curvos y fondo plano o pie anular bajo, con bordes sencillos o algo engrosados al exterior y con decoraciones en manganeso sobre fondos en melado o marrón (ACIÉN, CASTAÑO, NAVARRO, SALADO y VERA, 2003: 417-421). También en Córdoba recientemente se han documentado ataifores de escasa altura junto a otros más profundos, todos con borde simple, pero con vidriados complejos que incluyen tempranas producciones de verde y manganeso precalifal (SALINAS, 2013: 71, 76, 83 y fig. 11). En relación a esto, creemos muy interesante la excavación en Murcia del palacio califal de calle Fuensanta, bajo el cual se documentó un nivel de uso anterior a la construcción del edificio, sobre un estrato que contenía cerámicas que los autores fechan en la primera mitad del siglo X. En este contexto aparecieron algunas piezas que creemos transicionales entre lo emiral y lo califal, como dos ataifores muy similares a los del nivel inferior de Pechina, incluso con las características líneas incisas en la unión del fondo y la pared, aunque sin cubierta vítrea, solo con goterones de vedrío (BERNABÉ y LÓPEZ, 1993: 40-43 y fig. 15.2). Es interesante el hallazgo de un ataifor de perfil quebrado decorado con un motivo vegetal en verde y manganeso bajo cubierta vítrea verde-melada (BERNABÉ y LÓPEZ, 1993: 40-41 y fig. 15.2), una pieza que creemos relacionada con las primeras producciones de verde y manganeso, al igual que un ataifor del teatro romano de Cartagena (MURCIA y GUILLERMO, 2003: 207, 210 y fig. 19.138). Ambos ejemplares pueden ser de origen aglabí, tal y como se ha planteado para el de Cartagena, aunque también observamos similitudes con las piezas precalifales de Córdoba que recientemente se han dado a conocer (SALINAS, 2013). El resto de la cerámica hallada en los niveles antiguos de la calle Fuensanta también creemos que podría datarse entre lo emiral final y lo califal temprano.

También están vidriados otros fragmentos pertenecientes a formas cerradas de pequeño tamaño y difícil identificación. Podría pertenecer a un jarrito un borde engrosado al interior (Fig. 6, 2095-3), sobre todo por conservar un asa elevada similar a las que presentan estos recipientes en la segunda mitad del siglo

10. Si bien es difícil fechar con precisión el nivel inferior de Pechina, la conjunción de los datos históricos y los arqueológicos lo situaría en la segunda mitad del IX, aunque sus excavadores parecen inclinarse por una datación posterior al 884, que es cuando la ciudad cobra importancia (ACIÉN, CASTILLO y MARTíNEZ, 1990: 148-149; CASTILLO y MARTíNEZ, 1993: 69-70; ACIÉN, 1993: 169-170).

11. La datación del nivel de abandono de Pechina sería entre el 955, cuando Almería adquiere el estatus de capital de la Cora, a comienzos del siglo XI, cuando se produce su definitivo abandono (ACIÉN y MARTÍNEZ, 1989: 123-124; ACIÉN, CASTILLO y MARTÍNEZ, 1990: 148-149; CASTILLO y MARTíNEZ, 1993: 67 y 70). Según el almeriense al-'Uḍī, en 1011-1012 la población se trasladaría a Almería (AL-'UDRĪ, 1975-76: 35). 
IX, por ejemplo los de Pechina (CASTILLO y MARTíNEZ, 1993. p. 88 y lám. VI). Dos fragmentos vidriados en verde con acanaladuras al exterior (Fig. 6, 2095-5) quizás sean de una orcita o redoma. Finalmente, dos fragmentos vidriados en marrón, con borde exvasado y parte del arranque del asa (Fig. 6, 2102-10), posiblemente formaran parte del gollete de un candil, aunque también podrían corresponder a una redoma.

Las formas cerradas sin vidriar, principalmente aquéllas de pequeño tamaño, aunque también las mayores, presentan mayoritariamente decoración de filetes horizontales rojos similares a las de la fase anterior, y solo en un caso la decoración es pintada mediante digitaciones a la almagra (Fig. 6, 2071-29). Aunque en la mayor parte de al-Andalus las digitaciones aparecen ya en época emiral, en el sureste no las vemos asociada a los jarritos de los siglos VIII-IX y serán más habituales a partir del siglo X. En el Tolmo de Minateda no están claramente representadas hasta el horizonte IIIC, suma de contextos que podrían ir desde finales del siglo IX hasta lo califal (GUTIÉRREZ, GAMO y AMORÓS, 2003: 156, 157 y fig. 24) y, aunque en el nivel bajo pavimentos del ribāt de Guardamar coexisten las digitaciones y la decoración de filetes horizontales (GUTIÉRREZ, 2004: 76 y 79 y figs. 44 y 47), en Cartagena las digitaciones a la almagra no parecen estar presentes hasta los siglos X-XI (MURCIA y GUILLERMO, 2003: 212) y tampoco existen, hasta donde sabemos, en la Lorca emiral (MARTíNEZ RODRÍGUEZ y PONCE GARCÍA, 1995b). En Murcia, como ya hemos dicho, lo habitual es encontrarlas sobre grandes recipientes.

Como novedad, aparecen, pintados a pincel en rojo, motivos más complejos que los de la fase anterior. Con líneas finas a la almagra se trazan temas geométricos sencillos como bandas verticales rellenas de una línea ondulada (Fig. 6, 2095-9) y tramas reticulares (Fig. 6, 2071-5). Un fragmento de escaso diámetro, posiblemente perteneciente a un pico vertedor, presenta círculos enlazados dispuestos en vertical (Fig. 6, 2082-2). Esta decoración pintada a pincel fino, desarrollando motivos algo más complejos que los filetes paralelos, en el resto de al-Andalus tiene precedentes en lo emiral, si bien no hallamos correspondientes exactos en el siglo IX y sí en cambio en época califal (NAVARRO, 1990: 34 y 36 y figs. 5-6; ACIÉN, CASTILLO y MARTÍNEZ, 1990: 163; CASTILLO y MARTÍNEZ, 1991: 68-69 y lám. X.7; GUTIÉRREZ, 1996a: 160-163; MURCIA y GUILLERMO, 2003: 211 y fig. 20.146; PÉREZ BOTí, 2014: 59-60 y fig. 6). En el nivel inferior de la calle Pascual ya encontramos una pieza (Fig. 4, 2127-4) que repite los triángulos de líneas oblicuas, motivo que en Tudmirr se documentó en el El Zambo, "fechable a mediados del IX" (GUTIÉRREZ, 1996a: 107, 181, 160-163 y figs. 37 y 79.9). En la alcazaba de Madinnat Ilbìra, datada entre la segunda mitad del siglo IX y primer cuarto del X, se hallaron numerosos fragmentos de cerámica pintada con pincel fino en los que se representan motivos geométricos complejos, vegetales, epigráficos y figurativos, destacando aves a la almagra, composiciones triangulares, retículas e incluso sucesiones verticales de motivos ovalados como los que hemos visto en calle Pascual, que se detectan en los niveles más antiguos del despoblado granadino (CARVAJAL, 2008: 247-248, 288, 422, 430 y láms. 3, 11). Una pieza con motivo de piña se documentó en el Castillón, yacimiento que, a pesar de ser datado de manera laxa entre el siglo IX y primera mitad del X, presenta características plenamente emirales, como han resaltado diversos autores (MOTOS, 1993: 222, 227 y fig. 8.26). El arrabal de Cercadilla ha aportado temas geométricos en la etapa emiral, aunque aún incipientes (FUERTES, 2010: 207-209 y 652-655), al igual que los materiales procedentes de la excavación de un pozo ciego también cordobés datado a finales del siglo IX (SALINAS, 2013: 70, 82 y fig. 7). En Jaén se identificó un fragmento con decoración a la almagra casi idéntico a nuestra pieza 2071-5 (Fig. 6), que podría datarse desde el siglo IX a comienzos del X (PÉREZ ALVARADO, 2003: 162, 230, lám. 83 y figs. 343 y 346). En el Castellar de Alcoy, la revisión de los materiales emirales y califales de la excavación de los años sesenta, permitió documentar un tipo de ataifor de paredes divergentes y base plana, sin vidriar y con decoraciones a la almagra de círculos tangentes y líneas onduladas entre franjas verticales iguales a las nuestras, que ha sido 
encuadrado entre fines del IX y primera mitad del X (PÉREZ BOTÍ, 2014: 57-58, 64-66 y figs. 5, 9 y 10). Finalmente, en la propia ciudad de Murcia, en la secuencia estratigráfica de Belluga, encontramos motivos pintados complejos en una fase que creemos emiral avanzada.

El tratamiento de la superficie externa con engobe rojo también suele asociarse al período califal aunque tiene su origen en época emiral. Lo encontramos en dos de las piezas representadas (más una que no lo está), una de tamaño mediano, posiblemente un jarro (Fig. 6, 2071-7) y otra con decoración a pincel en blanco consistente en hojas lanceoladas concéntricas que penden de una línea ondulada que corre bajo el borde sobre un engobe rojo achocolatado (Figs. 6-7, 2095-23); se trata de un pequeño jarrito de perfil cilíndrico y con gran asa que supera la rasante del borde, cuya tipología recuerda a la de aquéllos doblemente carenados de la fase anterior y a los jarritos típicos de época emiral, aunque, como veremos, estas formas las seguimos documentando en época califal en Murcia y también hay algún ejemplar de Málaga y de Córdoba. El engobe en rojo se ha constatado en Córdoba ya en una época emiral temprana (CASAL, CASTRO, LÓPEZ y SALINAS, 2005: 193) y aparecieron piezas pintadas en blanco sobre engobe rojo en un pozo ciego con materiales datados a finales del IX; el motivo de las hojas lanceoladas concéntricas, aunque encadenadas y dispuestas en horizontal, se repite en varias piezas de ese conjunto, tanto pintadas como incluso vidriadas (SALINAS, 2013: 69-70, 72, 73, 82 84, 85, 87, 94, figs. 7, 13, 15 y láms. 2, 19) ${ }^{12}$. Es frecuente la aparición en Murcia de piezas con engobe rojo y pintura blanca aunque en contextos califales, así se pudo comprobar en el alfar de San Nicolás (NAVARRO, 1986: VIII) (Fig. 16, 1) y en el nivel de cimentación del palacio de la calle Fuensanta (BERNABÉ y LÓPEZ, 1993: 45, fig. 21.3). Sobre esto, hace años Gutiérrez (1996a: 274) señaló que se trata de una "producción califal típicamente cordobesa y del área del suroeste, que no aparece, que sepamos, en ningún otro asentamiento del sureste de forma representativa".

Por primera vez documentamos con total seguridad candiles, concretamente 9 fragmentos, pues los restos de las fases anteriores son dudosos. Uno de ellos completo (Figs. 7-8, 2095-22) apareció sobre el suelo de la cocina inferior junto al jarrito antes descrito; de manufactura algo tosca, presenta una gran cazoleta lenticular y alto cuello del que arranca el asa de pequeño tamaño. Su forma remite a otras que aparecen en un ambiente emiral final o ya califal ${ }^{13}$. Otro fragmento vidriado (Fig. 8, 2102-10) podría corresponder al gollete de un candil o de una redoma.

Un borde engrosado con refuerzo al exterior (Fig. 6, 2000-6) corresponde a un gran recipiente, de amplia boca, que podría ser una tinaja parecida a una registrada en el Tolmo de Minateda en un contexto de la segunda mitad del s. VIII, si es que nuestra identificación es correcta (AMORÓS, 2011: 73-74; CASAL, CASTRO, LÓPEZ y SALINAS, 2005: 203-204, 225 y fig. 14). También podría tratarse de un alcadafe o barreño, formas conocidas ya en época emiral aunque suelen ser más abiertas que lo que parece indicar el fragmento examinado (ACIÉN et al., 1991: 128; GUTIÉRREZ, 1996a: 94-95; PASCUAL, RIBERA y ROSELLÓ, 2003: 110, 112 y fig. 34; MURCIA y GUILLERMO,

12. Observamos un motivo muy similar, ya pintado en blanco sobre engobe rojo, en un jarrito procedente de Madînat al-Zahrā' custodiado en el Museo Arqueológico Nacional (no de inventario 63041); y pintado en blanco sobre engobe negro en una pieza cerrada procedente de Priego de Córdoba (CANO MONTORO, 2007: 154), en ambos casos la decoración se extiende sobre el cuello al igual que en la pieza murciana. En Silves se recuperaron varias piezas con engobe rojo y pintura blanca de perfil similar a las nuestras pero con dos asas, a las que se ha dado una fecha como mínimo discutible de los siglos VIII y IX (VARELA, 1992: 28, 30 y fig. 6); son idénticas a otras de la cercana Mértola que sin embargo se han datado en el siglo XI, donde además se señala que pueden aparecer con un solo asa (CANDÓN, GÓMEZ, MACÍAS y RAFAEL, 2001: 560 y 565, fig. 4.4).

13. Aunque encontramos similitudes con candiles que aparecen en el arrabal cordobés de Cercadilla en un período de transición, entre fines del IX y principios del X, éstos tienen la piquera más corta y la mayoría el gollete menos elevado (FUERTES, 2010 : 132 y fig. 257); también observamos semejanzas con algunos ejemplares califales (FUERTES, 2010: 129-130 y figs. 252-253). Vemos una pieza muy similar en el nivel emiral de Pechina (CASTILLO y MARTÍNEZ, 1993: 98 y lám. XII.2). También se asemeja a los candiles emirales de Málaga (í̃NIGUEZ y MAYORGA, 1993: 129, lám. 7). 


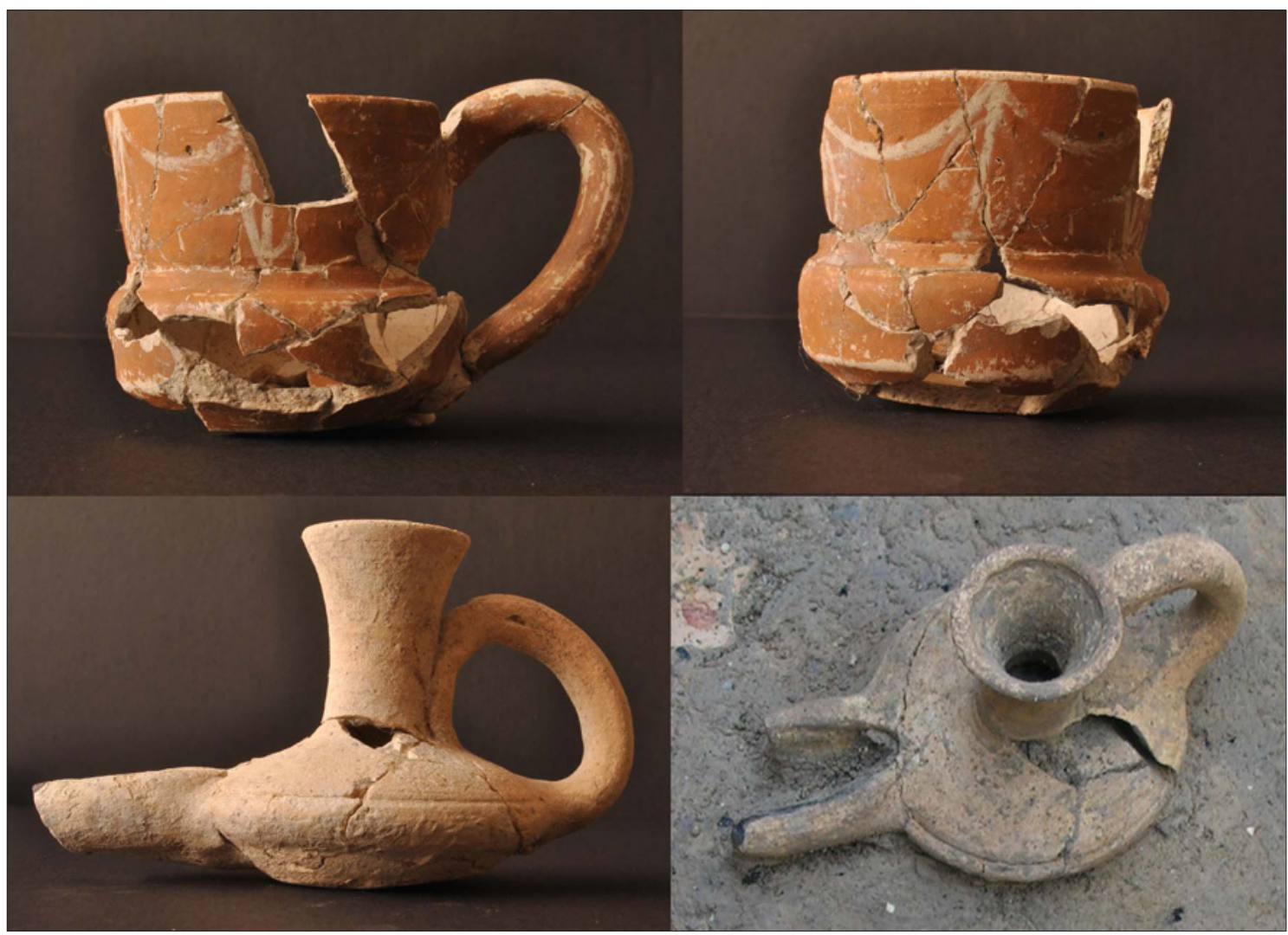

Fig. 7. Piezas completas halladas sobre el nivel de uso de la cocina de la fase Illa.

2003: $205-206$ y fig. 18.125. Hemos reconocido dos piezas como alcadafes, aunque no estamos completamente seguros. Una es de gran tamaño y está realizada a mano (Fig. 8, 2071-14); formalmente podría ser una cazuela pero no tiene marcas de fuego y su interior se encuentra engobado y alisado, acabado propios de los alcadafes que no encontramos en la cerámica de cocina. Se asemejan bastante a esta pieza las formas a mano 27.4.1 y 27.4.2 de Gutiérrez (1996a: 92-94), datadas entre fines del siglo IX y X, clasificadas como ataifor o alcadafe. La otra es menor y fabricada a torno (Fig. 8, 2095-18); podría parecer un cuenco si no fuera por su factura tosca.

Hay tapaderas de un solo tipo: planas, de borde engrosado y pellizcado con asa de puente, en distintos tamaños, casi siempre con evidencias de exposición al fuego en la base (13 fragmentos).

El ajuar de cocina destaca por la amplia representación de las marmitas de borde entrante, con distintos tamaños, siempre con decoración incisa a peine generalmente ondulada; en total hallamos 111 fragmentos, lo que supone un $17,37 \%$ de lo recuperado. En ese panorama homogéneo solo hay dos excepciones: en primer lugar, un borde de una pieza de boca lobulada con pestaña al interior (Fig. 8, 2071-11). En segundo, el galbo de un alto recipiente cerrado con líneas de torno muy marcadas (Fig. 8, 2095-14) que tipológicamente recuerda a los jarros; no obstante, el arranque de un cuello abierto, su pasta refractaria, cocción alternante y superficie externa ahumada con evidencias de exposición al fuego, nos llevan a pensar que desempeñaba una función culinaria. Dadas las peculiares características de la manufactura de esta pieza, que no se asemeja al resto de cerámicas, no solo de este contexto, sino de todo el yacimiento, consideramos que se trata de una importación. A pesar de no conocer la pieza completa, y aunque no se puede descartar que se tratara de una variante de alguno de los tipos presentes en Tudmìr (GUTIÉRREZ, 


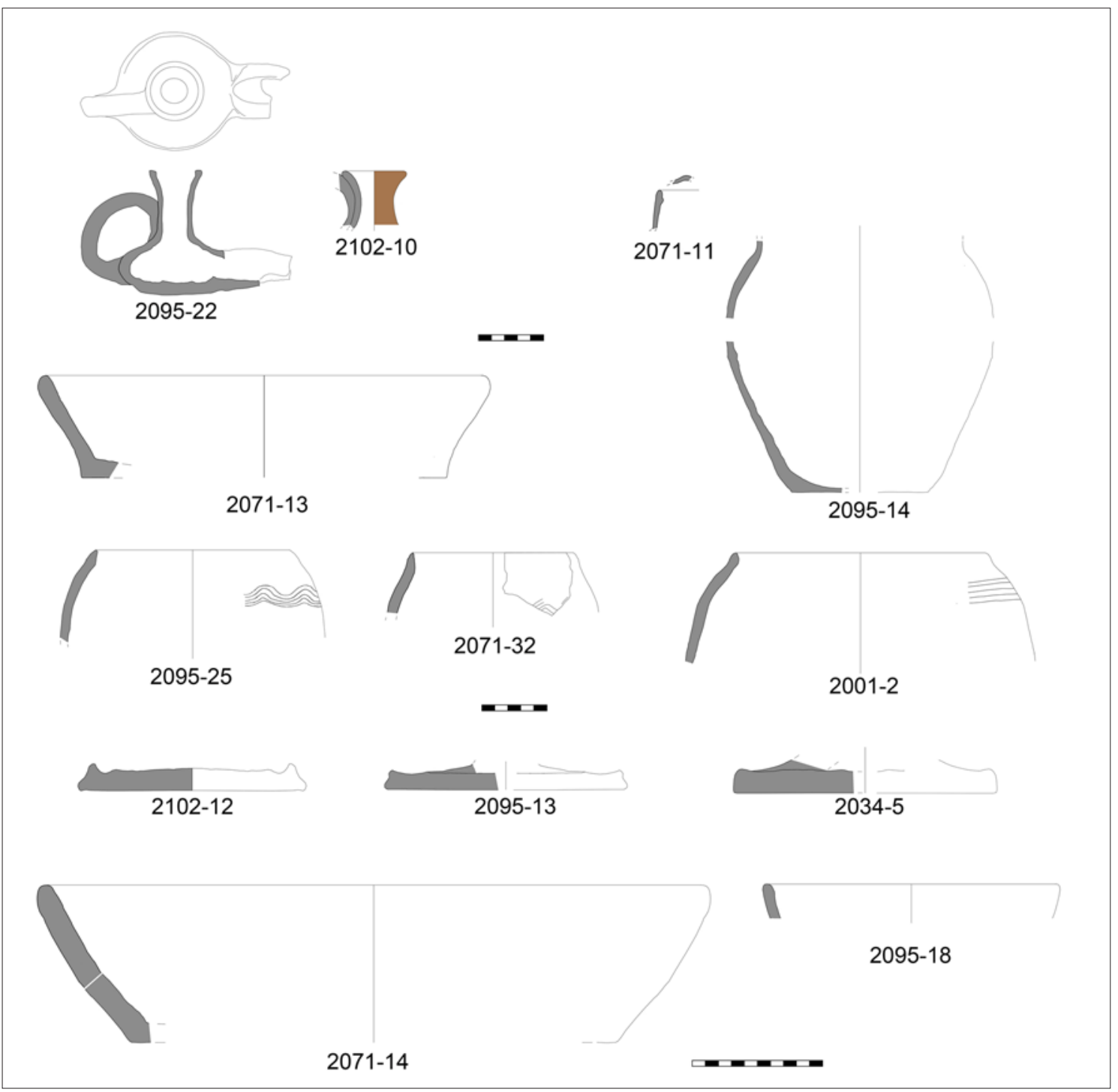

Fig. 8. Cerámica de las Fases III-IV. Formas de cocina, iluminación y usos múltiples y complementarios.

1996a: 98-99; AMORÓS, 2011: 114-115, 179-180 y figs. 65 y 140), encontramos mayores semejanzas con piezas de Andalucía oriental, como las de Pechina y Cártama (Málaga), en donde son muy abundantes en contextos emirales, pero no en los califales (CASTILLO y MARTíNEZ, 1991: 65-66; MELERO, 2009: 34-35, 45 y fig. 4; CASAL, CASTRO, LÓPEZ y SALINAS, 2005: 217 y fig. 1.30; MOTOS, 1993: 212-218; MALPICA, JIMÉNEZ y CARVAJAL, 2010: 1850 y fig. 1).

Hay, al menos, una cazuela fabricada a mano (Fig. 8, 2071-13), que corresponde a uno de los tipos más habituales en época emiral y que pervivirá en época califal; en concreto es muy similar a una hallada en Lorca en un con- texto del IX (MARTÍNEZ RODRÍGUEZ y PONCE GARCÍA, 1995b: 303, 305 y fig. 6.2) y otras de finales del período, como una recuperada en el nivel I de Pechina (CASTILLO y MARTíNEZ, 1993: 80, 83 y Lám. III.2); una de la basílica de Algezares, correspondiente a la forma M8.4 de Gutiérrez y datada entre fines del IX y primera mitad del X (GUTIÉRREZ, 1996a: 84-85); y otra, más reciente, del Horizonte IIIb del Tolmo, clasificada como forma M8.3 (GUTIÉRREZ, GAMO y, AMORÓS, 2003: 153-154 y fig. 22.1; AMORÓS, 2011: 183 y fig. 142).

También hay que hacer referencia a varios tannures localizados in situ, en el interior de los hogares forrando sus paredes, pero en un 
estado de degradación tan acusado que solo podremos reconstruirlos cuando previamente sean consolidados y restaurados. Responden al tipo básico de perfil troncocónico, abierto en los extremos.

Otro tipo que tenemos bien representado ya en estos niveles es el cangilón o arcaduz ${ }^{14}$, que servía a norias de corriente o de sangre (aceñas). Aunque muy fragmentados, al menos podemos individualizar 4 ejemplares, uno de ellos con una base con pie, similares a los documentados por Gutiérrez para el área del bajo Segura a partir de mediados del siglo VIII y durante la centuria siguiente; a los que considera como valiosos indicadores del proceso de islamización (GUTIÉRREZ, 1996b: 10-12). En el transcurso de las numerosas excavaciones que se han llevado a cabo en la ciudad de Murcia sólo se han identificado 5 pozos de aceña, de los que al menos 3 estaban asociados, con total seguridad, a baños (JIMÉNEZ, 2013: 596 y 597). Cada casa contaba con su pozo, pero para extraer el agua no se utilizaban ingenios hidráulicos debido a que el nivel freático se hallaba muy superficial; por tanto, la relativa abundancia de este tipo de recipientes en fases tempranas como las que nos ocupan, creemos que podría estar asociada más bien a la agricultura de regadío.

Estos contextos de la calle Pascual nos parecen especialmente interesantes por su ubicación estratigráfica, bajo niveles ya claramente califales y sobre otros emirales del siglo IX. Además, detectamos dos fases de cocina superpuestas (fases III y IV), la inferior (III) con al menos dos niveles, todo lo cual demuestra una cierta perduración en el tiempo. También nos parecen relevantes por la amplia representación de formas, con algunas piezas enteras y halladas sobre el primer suelo de la cocina inferior (fase IIla), que debió de tener un final repentino antes de ser reconstruida. Los materiales remiten, por un lado, a ambientes de finales del siglo IX de Andalucía central y oriental (ataifores de Málaga, Pechina y Córdoba); pero, por otro, muestran rasgos que se suelen datar, sobre todo en Levante, en el siglo X, como las digitaciones pintadas a la almagra, las decoraciones complejas a pincel fino (si es que efectivamente hay que encuadrarlas en este conjunto); $y$, sobre todo, la presencia de los ataifores vidriados. Incluso hay un jarrito ornamentado en blanco sobre engobe rojo, que se relaciona con decoraciones típicamente califales cordobesas aunque con precedentes emirales. Estos rasgos aparentemente contradictorios aparecen ya en el ajuar del nivel de la amortización de la fase Illa, el más antiguo de los que ahora tratamos. En conclusión, pensamos que se sitúan, en líneas generales, en un ambiente de transición entre las épocas emiral y califal. Por todo ello, y teniendo en cuenta el resto de la estratigrafía, proponemos, que la actividad doméstica asociada a estos niveles pudo comenzar entre el último cuarto del siglo IX y principios del siglo $X$, posiblemente cerca del cambio de siglo, para extenderse al menos durante la primera mitad, y quizás también el tercer cuarto, del siglo X. Con seguridad estos materiales son anteriores a las fases califales plenas o tardías, representadas por una fosa que sesgará toda la estratigrafía y otra cocina superpuesta (fase V).

Hay que hacer referencia a la aparición de la mitad de un ponderal de vidrio con epigrafía en el nivel de destrucción de la cocina de la fase antigua (IIIa). Actualmente se encuentra en estudio y esperamos que pueda realizarse una lectura de su escritura e incluso aporte una datación. Este tipo de piezas se utilizaban como medida para contrastar el peso de las monedas y también, según algún autor, pudieron funcionar como circulante ante la ausencia o escasez de moneda metálica (BATES, 1981). Son muy habituales en Egipto e Ifriqiya en época fatimí (siglo X), pero también fueron acuñadas en esa región anteriormente, ya desde época bizantina, bajo los omeyas y los aglabíes; así como posteriormente, en tiempos de los ayyubíes. No conocemos, sin

14. Aunque en la secuencia que estudiamos no identificamos arcaduces en las fases anteriores, sí que se halló al menos uno en otro sector de la excavación en relación con la fase II. 
embargo, ninguna pieza de este tipo procedente o hallada en al-Andalus. Hemos consultado sobre ella a dos especialistas por separado, los doctores Carolina Doménech y Salvador Peña quienes, de manera preliminar y con muchas reservas, coinciden en que recuerda a los ejemplares fatimíes del siglo $X$, en concreto a los del califa fatimí al-Mu'izz, quien gobernó desde el 953 al 975. De confirmarse esta fecha, supondría que la primera cocina emiral estuvo en uso como mínimo hasta mediados del siglo X (final de la fase IIlb), por lo que la fase IV habría que datarla en época califal plena.

Por último, contamos con dos dataciones de $14 \mathrm{C}$ procedentes de tizones de hogares de las cocinas de las fases IIIa y IV que arrojan fechas prácticamente idénticas: se remontan al siglo IX, aunque alcanzan, con escasas probabilidades, a los dos primeros tercios del siglo X. De nuevo el límite post quem que proporciona el $14 \mathrm{C}$ es poco preciso. En cualquier caso, las cerámicas halladas y estudiadas de esta fase IV son escasas. Albergamos esperanzas de que el estudio que hemos iniciado recientemente de los materiales de la Plaza de Belluga nos ayude a conocer con más precisión este intervalo de 75 años entre la cerámica emiral final hasta el ajuar califal pleno.

\section{Fase V}

Esta fase nos aporta abundante cerámica, con piezas completas que se hallaron rellenando una fosa (Fase Va, UUEE 2101 y 2110). Dicha fosa rompe los niveles de las cocinas anteriores de época emiral y califal temprana, y quedó sellada por una reconstrucción de la vivienda, incluida una nueva cocina (UE 1930) con un primer nivel de uso (Fase Vb, UUEE 1822, 1810), y posteriormente una elevación de suelo con nuevos horizontes de uso asociados (Fase Vc, UE 1793). Casi toda la cerámica que presentamos proviene de la fosa previa al uso de la cocina (561 fragmentos), por tanto del nivel inicial de esta fase (Va), dado que los niveles superiores aportaron materiales escasos y muy fragmentarios (41 de la fase Vb y 121 de la $V c)$.

Los jarros y jarritos (Fig. 9) son recipientes destinados al consumo directo de líquidos cuya capacidad oscila entre 0,1 y 2 litros (Fig.

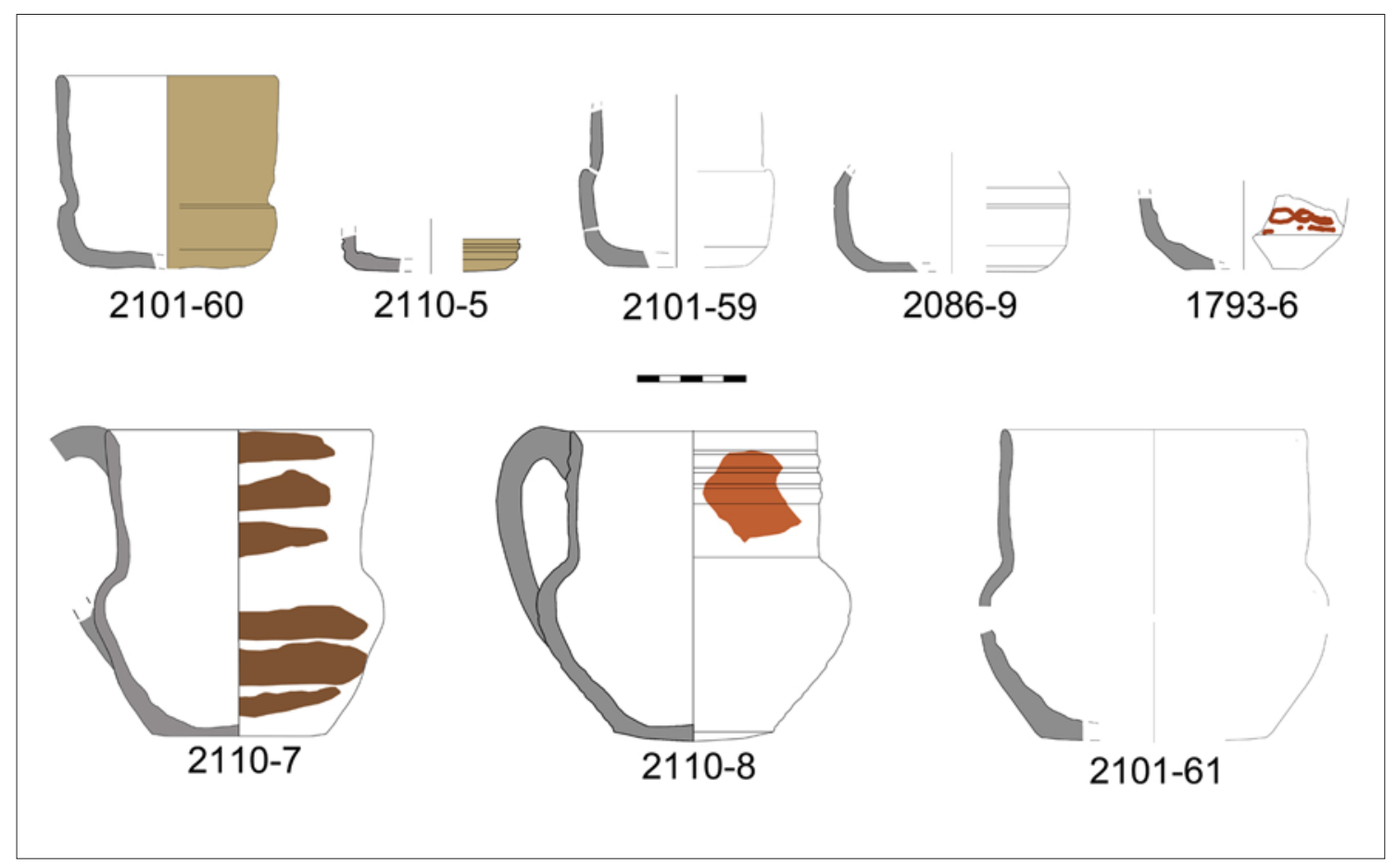

Fig. 9. Cerámica de la Fase V. Jarritos y jarros. 
10) ${ }^{15}$. Se trata de un vaso para beber bastante generalizado en la cultura andalusí al menos de los siglos IX a principios del XI ${ }^{16}$. Las formas menores suman 185 fragmentos en el nivel $\mathrm{V}$, lo que supone un $25,58 \%$ del total de piezas; la proporción, aun siendo alta, es inferior a la de los niveles anteriores. Presentan una serie de elementos morfológicos básicos destinados a facilitar su uso: cuello y boca ancha y circular, sin picos vertedores ni piqueras, y un asa. Muestran diferentes tratamientos y acabados, pero el volumen interno permite distinguir dos series distintas: los jarros y jarritos, que también presentan distintos perfiles: de tendencia cilíndrica en los menores y globular en los mayores. Además, los jarritos suelen estar hechos con unas arcillas más depuradas y un torneado más fino de las paredes, junto a una decoración más compleja. En época califal algunas variedades de jarros empiezan a dotarse de dos asas, convirtiéndose en el tipo que en la historiografía ceramológica se ha denominado como jarritas, que son cada vez más abundantes a partir del siglo
XI sustituyendo progresivamente a los jarros y jarritos como recipientes destinados a ese fin. Desde los niveles emirales de la calle Pascual (Fase II, 850-900) ya distinguíamos por sus dimensiones los jarros de los jarritos. Estas características se mantenían en la fase III (900-975) y también en la que ahora nos ocupa, la fase V. De hecho, el hallazgo en este nivel de varios ejemplares cuyo estado de conservación posibilita restituir su perfil, nos va a permitir analizar estas formas y sus tipos con mayor detalle.

Al igual que suceden en el alfar de S. Nicolás (Fig. 16, 11-13) los jarritos de calle Pascual se pueden agrupar en dos subtipos atendiendo a su tamaño: el primero corresponde a recipientes de $7 \mathrm{~cm}$ de base por $7 \mathrm{~cm}$ de altura, aproximadamente, y una capacidad en torno al cuarto de litro; el segundo lo conforman jarritos de alrededor de $10 \mathrm{~cm}$ de base por 10 $\mathrm{cm}$ de altura y un volumen de medio litro (Fig. 10). En ambos casos estamos ante piezas de perfil cilíndrico, con marcadas acanaladuras

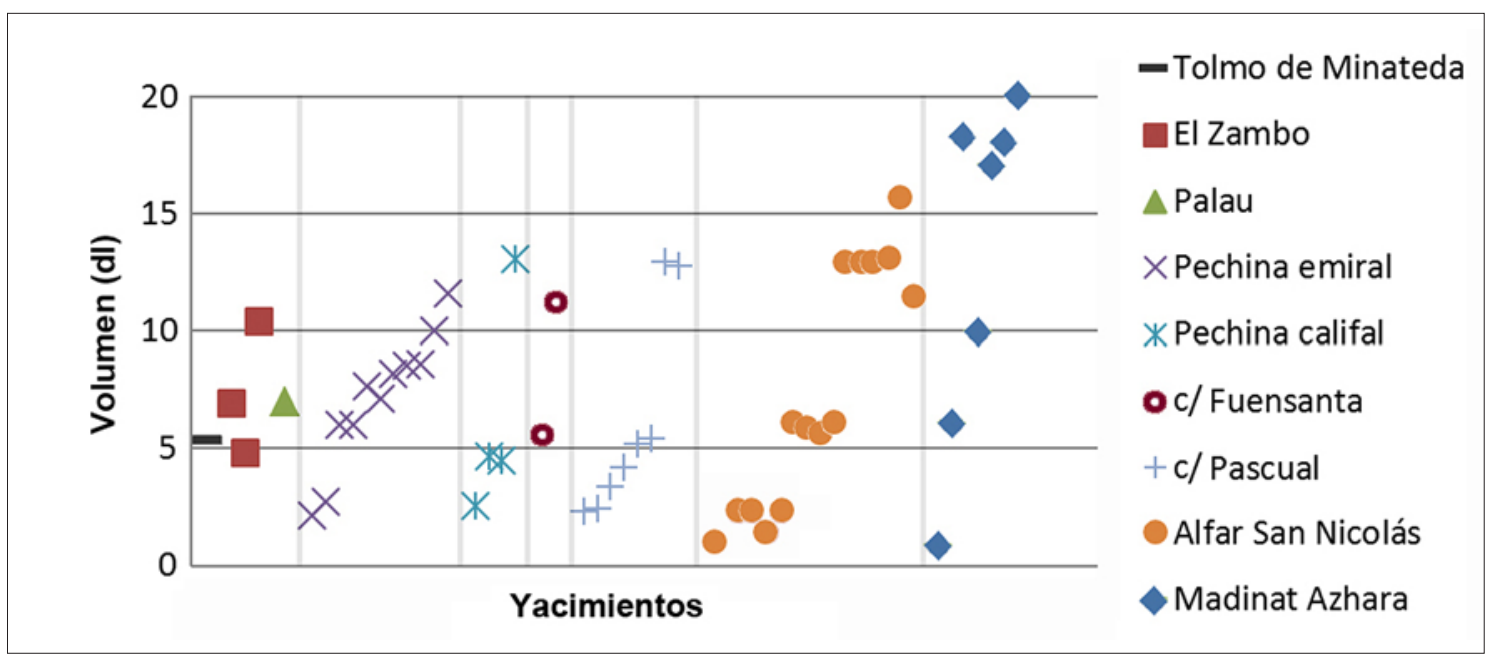

Fig. 10. El gráfico incluye jarros y jarritos de diversos contextos andalusíes desde el siglo IX al X (50 piezas), que aparecen ordenados en el eje de ordenadas $(X)$ según contextos y cronologías. El volumen es expresado en decilitros en el eje de abscisas.

\footnotetext{
15. La figura 10 es un gráfico orientativo y parcial de los recipientes para el consumo de líquidos. De Madīnat al-Zahrā' se ha contado con los jarros y "cuencos" publicadas por Escudero y Vallejo (1999); de la calle Fuensanta con las dos piezas de perfil completo adscritas a época califal (Fig. 21.1 y 21.2); el mismo criterio se ha seguido para el alfar de San Nicolás y Pechina, en este último caso dividido en los dos niveles de la excavación (CASTILLO y MARTíNEZ, 1993). Para el Zambo, Minateda y Palau hemos utilizado los materiales publicados por Gutiérrez (1986: fig. 13; id., 2011: Fig. 5). De calle Pascual hemos incluido todas las piezas de la fase $\checkmark$ y el único jarrito completo de la fase III. En algunos casos se ha restituido el volumen al presentar la pieza incompleta unas dimensiones y tipología idénticas a otras completas.

16. En el estudio del material de Mértola, Susana Gómez define los jarritos pequeños para beber y los relaciona con los púcaros de siglo XIV, que tendrían todavía un valor de medida (GÓMEZ, 2004: 479, figs. 62 y 63).
} 
que delimitan las diferentes partes de la pieza: base, cuerpo y cuello. Habitualmente están decorados, en las fases anteriores a pincel fino con motivos complejos (fase II) y engobe rojo (fase III), y ahora en la fase $V$ también vidriados (Fig. 9, 2101-60 y 2110-5), uno de ellos sobre superficie acanalada. Otro ejemplar de esta fase finalmente tiene decoración pintada a la almagra (Fig. 9, 1793-6). Hay que destacar que casi todos se hallaron en el nivel inferior, en la fosa, mientras que solo este último, que presenta un perfil algo diferente por una inflexión a la altura del talón que da lugar a una base más estrecha, se encontró en el nivel de uso de la cocina superior (Fig. 9, 1793-6). A falta de un análisis profundo, observamos que esta tendencia también parece darse entre los jarritos del sondeo de la plaza del Cardenal Belluga. La serie de jarritos que venimos estudiando en la calle Pascual muestra que ya existían desde el siglo IX, pero también aclara que perdurarán, estando bien representados en los contextos posteriores. Son muy parecidos a algunos de los jarritos hallados en San Nicolás, en concreto a los menores, con los que coinciden en tamaño (Fig. 16, 12-13) (NAVARRO, 1986: 146, 156-157, n० 309- 310, 336, 338- 339; id., 1990: fig. 7.1 a 7.7; NAVARRO y GARCÍA, 1989: 326, fig. 7.1 a 7.7) y en tratamiento ya que los del alfar se consideraron, en general, como desechos antes de una segunda cochura y en Pascual al menos dos están vidriados. Más allá de Murcia esta forma se detecta en otros contextos andalusíes datados entre la segunda mitad del siglo X y principios del XI ${ }^{17}$.

Los jarros tienen un tamaño aproximadamente un 50 \% mayor que los jarritos, y un volumen bastante superior, ya que los dos más pequeños están en torno al litro y cuarto de capacidad. Morfológicamente son muy distintos, ya que tienen un cuerpo globular o piriforme invertido rematado por un cuello cilíndrico, alto y bien diferenciado. Suelen presentar marcadas líneas de torno o incluso acanaladuras (Fig. 11). Como los jarritos, los

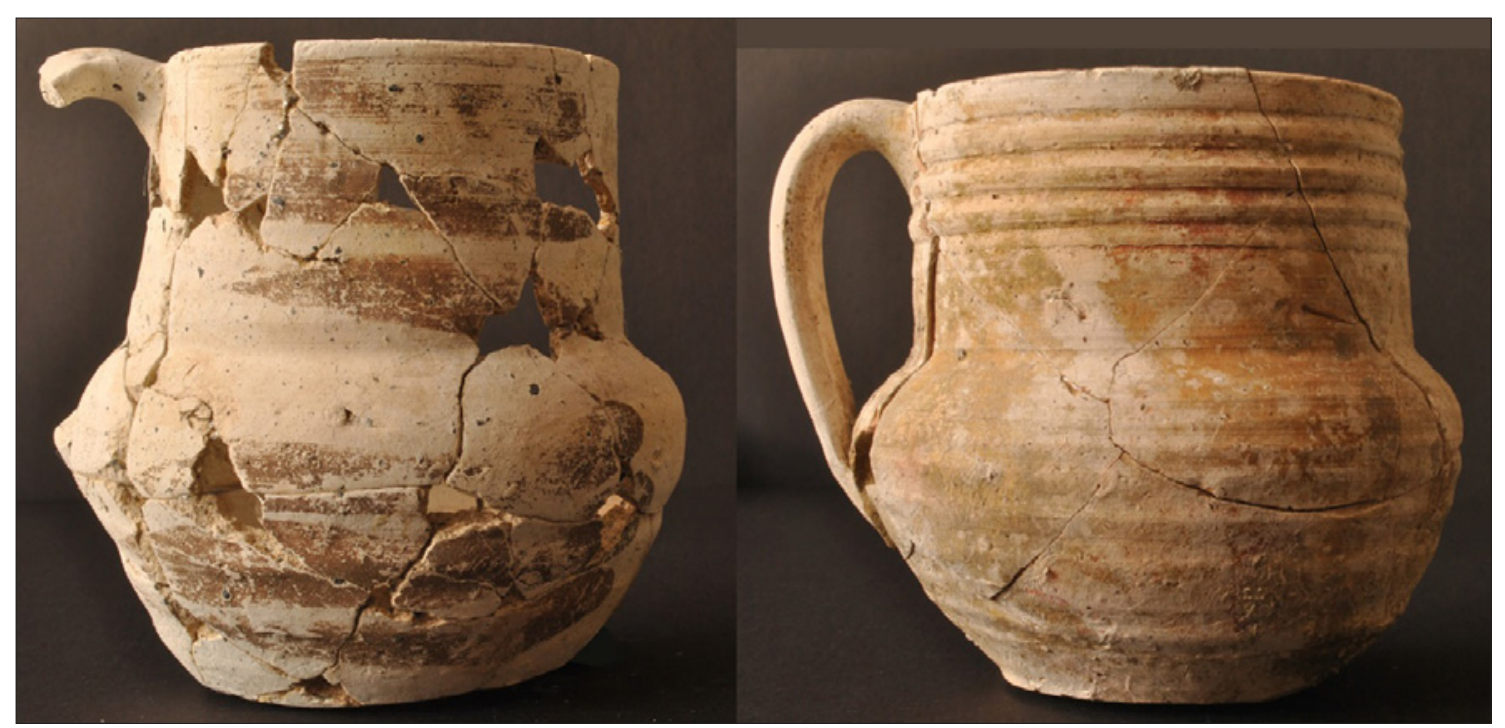

Fig. 11. Cerámica de la Fase V. Jarros bizcochados.

17. La continuidad del tipo de pequeño jarrito cilíndrico ya había sido señalada en una puesta en común de los materiales del sureste de al-Andalus, señalándolo como una reducción de los anteriores emirales (ACIÉN et al, 1991: 127). Los jarritos pequeños con perfil cilíndrico, vidriados y decorados en verde y manganeso están presentes en Cercadilla (FUERTES, 2002: 44, 46, 235, 271, fig. 14 y lám. 6) y en Cártama (Málaga) (MELERO, 2009: 38, 48 y fig. 7.17) En Madinnat al-Zahrā’ podemos observar unas piezas menores de perfil cilíndrico, que con cuerpo muy reducido en altura, no demasiado distinto a algunos tipos de los comentados de Murcia, desarrollan su base, lo que unido a la ausencia de asa ha dado lugar a que se identifiquen como cuencos o jofainas; aparecen cubiertos de engalba roja y con pintura blanca (VALLEJO y ESCUDERO, 1996: 135 y 149 y figs. 1). Finalmente se puede señalar por su semejanza a los ejemplos murcianos, las abundantes jarritas del sur portugués califal, con el tratamiento anterior y de perfil también cilíndrico e igualmente pequeñas dimensiones (CANDÓN et al., 2001: 565). En Silves fueron datados, a nuestro juicio de manera errónea, en época emiral (véase GOMES, 1992: 28, fig. 6). 
hallamos también en fases previas, aunque presentan algunas diferencias en cuanto a la decoración: en los más antiguos (I a III) es de finos filetes de almagra y luego comienzan a recibir trazos gruesos o digitaciones (fases III y V), decoración antes reservada para las grandes jarras de almacenaje y acarreo. En el nivel que nos ocupa se hallaron dos ejemplares casi completos, de perfil prácticamente idéntico (Fig. 9, 2110-7 y 2110-8), que, sin embargo, presentan otras características técnicas y decorativas particulares: las pastas son distintas y uno de ellos tiene el cuello marcadamente acanalado (2110-8); mientras que el cuerpo del otro presenta una superficie ondulada por las marcadas líneas de torno (2110-7). El tratamiento decorativo es de digitaciones a la almagra, en el segundo, y una gruesa mancha de almagra sin forma definida, en el primero. La tercera pieza (Fig. 9, 2101-61), de mayor tamaño, pudo tener un perfil similar a las anteriores.

Las jarras (Fig. 12) están mayoritariamente realizadas a torno, salvo un ejemplar a mano (Fig. 12, 2101-28). Se conserva casi completa una de paredes bastante finas en relación a su tamaño (Fig. 12, 2110-17), que presenta una pasta amarilla verdosa, con desgrasantes oscuros de gran tamaño, que se deshace con facilidad. Su decoración pintada a la almagra mediante finas líneas horizontales recuerda a la típica de la época emiral, aunque ahora presenta como novedad un tono vinoso y una línea ondulada bajo el borde. Estos detalles aparecen en varias piezas de distintos contextos del sureste; en Cartagena se encuentra en conjuntos fechados a finales del S. IX y en niveles posteriores (GUTIÉRREZ, 1996a: 160-163, 181-182, 235, 282 y 353; MURCIA y GUILLERMO, 2003: 205, 206, 208 y fig. 18.), y también creemos que la parte superior de una hallada en el alfar antiguo de San Nicolás presentaba una decoración similar (Fig. 16, 10) (NAVARRO, 1990: fig. 8.22). El borde y cuello de otra jarra (Fig. 12, 2101-25) muestra decoración a la almagra de aspas entre metopas, motivo decorativo que, inciso bajo cubierta vítrea, ya existía en la Málaga emiral (î̃NIGUEZ y MAYORGA, 1993: 126-128 y lám. 5.12), y estuvo muy extendido en época califal: lo hallamos en Ilbīra (CANO, 1990: 29-31, 62, 65, fig. 5.2069, 8); pintado en otros conjuntos inéditos de Andalucía oriental y, sobre todo, está en el Šarq al-Andalus. Gutiérrez planteó que esta decoración pintada a pincel se relacionaba con momentos avanzados, de la segunda mitad del X o comienzos del XI (GUTIÉRREZ, 1996a: 160-163), y en Elche se recuperaron materiales de un alfar fechado a fines del $X O$ primera mitad del XI entre los que se encontraban fragmentos con esta decoración (AZUAR y MENÉNDEZ 1999: 681, 682, 686, 687 y lám. 2.3). En Mallorca aparece un motivo de aspas sobre el cuello de una jarra, muy parecido, aunque que no exactamente igual, en un contexto de mediados del siglo $X$ o de la segunda mitad de dicho siglo (RIERA, 1999: 186 y fig. 6.9; ROSSELLÓ, 2002: 181).

En Tudmìr se ha demostrado la amplia existencia del jarro de una sola asa en época paleoandalusí, mientras que la presencia de dos asas (jarrita) se generalizará en los contextos califales (GUTIÉRREZ, 2007: 602). Así, en las publicaciones de San Nicolás está representado un solo jarro y tres piezas con dos asas (Fig. 16, 15) (NAVARRO, 1986: 155, no 332-333; id., 1990: Fig. 7.9), y el nivel sobre el que se funda el palacio de la calle Fuensanta, datado a mediados del X, ofrece solo jarritas (BERNABÉ y LÓPEZ, 1993: 42-45). LO mismo puede observarse en las producciones del alfar de Pedro de la Flor (Murcia), seguramente ya del s. XI (MUÑOZ y CASTAÑO, 1995), y en otro de Lorca, destruido según los arqueólogos a mediados del siglo X, el cual producía abundantes jarritas mientras que los jarritos son menos numerosos (MARTíNEZ y PONCE, 1995a: 150, 151 y 153). Lo mismo que parece suceder, en general, en el sureste de al-Andalus (ACIÉN et al., 1991: 127); así resulta significativo que bajo los pavimentos de la fase segunda del ribāt de Guardamar, horizonte datado con anterioridad al 944, se documentan jarros, mientras que las jarras son la única forma en los niveles de abandono fechados entre la segunda mitad del Xy primer tercio del siglo XI (AZUAR, 1989a: 46, 52, 118 y 119; GUTIÉRREZ, 2004: 73-87; MENÉNDEZ, 2004: 115, 117 y 119). También en Mallorca se vio con claridad esta evolución, ya que allí se 
detectan jarros en los contextos emirales, pero en el nivel califal, que según Rosselló estaría datado en torno al 940, han sido sustituidos por las jarritas (RIERA, 1999: 179, 187 y Fig. 7; ROSSELLÓ, 2002: 181). Aunque los jarros constituyen un buen marcador de la evolución del ajuar cerámico pues parece apreciarse su desaparición progresiva, o tendencia a desaparecer, durante los siglos X y XI, aún aparecen bien representados como muestran los ejemplares murcianos e incluso el nivel califal de Pechina (CASTILLO y MARTíNEZ, 1993: 109 y lám. XVIII). Su presencia en la fase V de calle Pascual, podría interpretarse como un rasgo de relativo arcaísmo. Observamos que la progresiva adición de dos asas podría nacer de la necesidad derivada del incremento en la envergadura del recipiente; así, por lo general, las formas que llevan dos asas suelen tener volúmenes a partir del litro y medio.

Distinguimos de los jarros para beber aquéllos que fueron utilizados para verter o escanciar (Fig. 12). La variedad de formas y tamaños es amplia, respondiendo cada una a diferentes contenidos, usos y necesidades. Una pieza se caracteriza por tener un asa, el cuello exvasado y presenta una boca

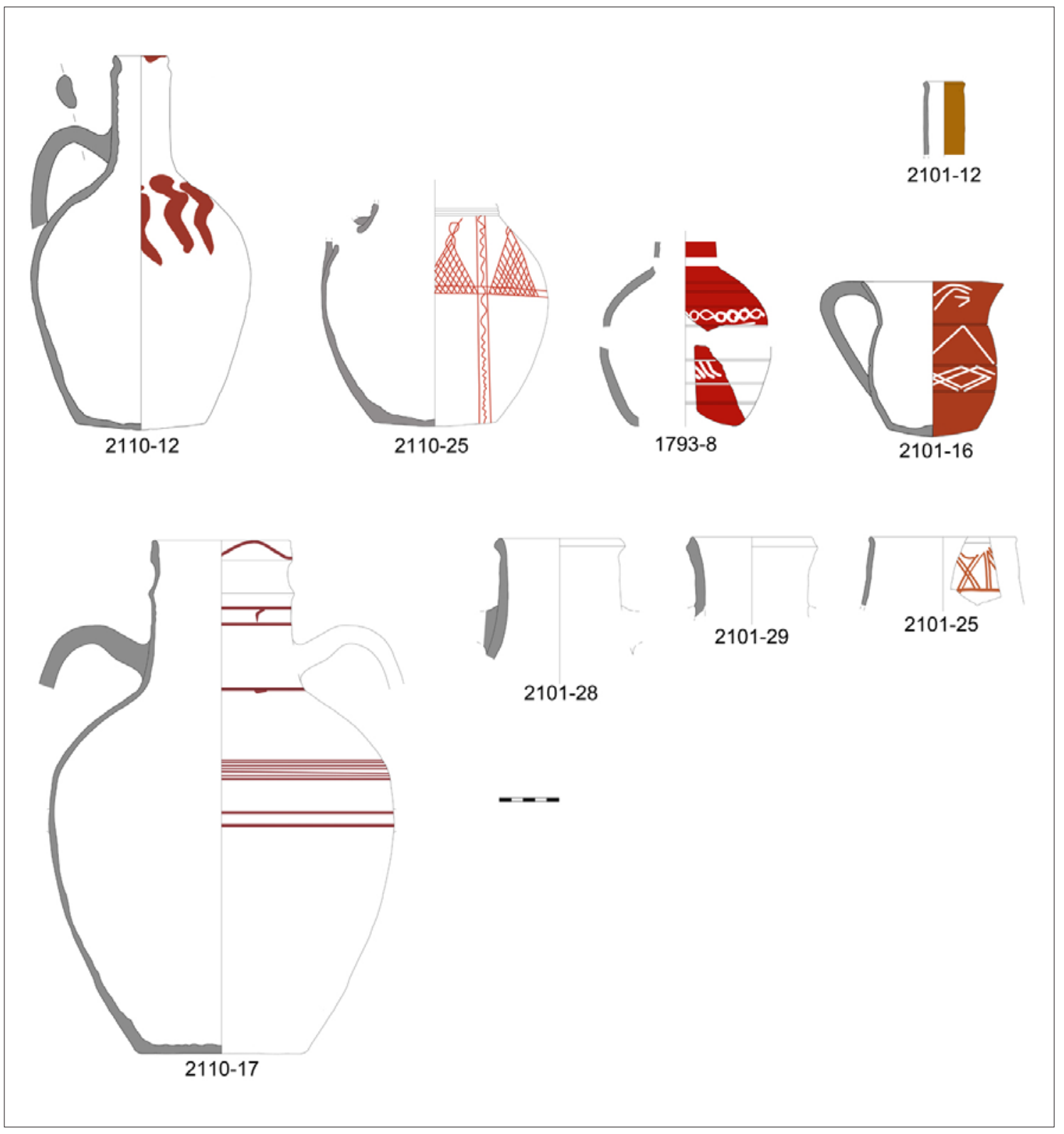

Fig. 12. Cerámica de la Fase V. Formas para servir y conservar. 
pellizcada para conformar un pico vertedor; la decoración es de engobe rojo con trazos blancos de diseño geométrico (Fig. 12, 210116). Recuerda a piezas similares en cuanto a forma y decoración de Madinat al-Zahrā', aunque la nuestra muestra un cuello más ancho (VALLEJO y ESCUDERO, 1996: 136-137 y figs. 7-10); así como a varias procedentes del alfar de San Nicolás, una de ellas también con pintura blanca sobre engobe rojo (Fig. 16, 2) (NAVARRO, 1990: 36 y 39 y fig. 7.13 ). La forma puede rastrearse en el sureste desde época emiral con distintas variantes, como la Forma T18 de Gutiérrez (1996a: 111-112). Otra variedad la representa el jarro de boca estrecha decorado con digitaciones ondulantes a la almagra (Fig. 12, 2110-12), muy similar a una "redoma" procedente de Madinat al-Zahrā' (VALLEJO y ESCUDERO, 1996: 135, 149 y fig. 2.1; GÓMEZ-MORENO, 1951: 311), un tipo bien establecido en época califal con distintos tratamientos (ACIÉN et al., 1991: 315, Fig. 376.g). También documentamos un jarro con arranque de un pitorro desde el hombro y con decoración de trazos finos a la almagra que forman sectores triangulares reticulados y franjas verticales rellenas de líneas ondulantes (Fig. 12, 2110-25). La forma es también típicamente califal ${ }^{18}$, y está especialmente bien representada en Madinnat Ilbīra (CANO, 1990: 28-29, 61 y fig. 4.767; CARVAJAL, 2008: 463, lám. 44; GÓMEZ-MORENO, 1951: 317 y fig. 378). Zozaya los denominó aguamaniles $y$, decorados en verde y manganeso, los consideró como producciones califales inspiradas en otras orientales (ZOZAYA, 1980a: 275, 277 y fig. 9b; ACIÉN et al., 1991: 126). Hay que destacar su similitud con otras piezas de Alicante y Murcia fechadas entre los siglos X y XI, y que tienden a decorarse de manera similar ${ }^{19}$. Muy semejante al nuestro es uno hallado en el alfar de San Nicolás (Fig. 16, 6) (NAVARRO, 1990: fig. 7.18). También es preciso recordar el posible precedente de un pitorro de la fase anterior (Fig. 6, 2082-2) que, si bien pertenece a una forma más pequeña que los aguamaniles califales, presenta la misma decoración que la pieza de Alcoy.

Podría pertenecer a una botella o redoma un alto y estrecho cuello vidriado (Fig. 7, 210112), que responde a un tipo habitual que ya aparece abundantemente en el nivel emiral de Pechina (CASTILLO y MARTÍNEZ, 1993: 9293 y lám. IX), en Málaga (IINIIGUEZ y MAYORGA, 1993: 126-127, lám. 5) y en el Zambo (GUTIÉRREZ, 1996a: 109), y también en contextos califales igualmente de manera abundante: en Madinnat al-Zahrā' (VALLEJO y ESCUDERO, 1996: 135, figs. 2 y 3), en Cercadilla con bordes engrosados (FUERTES, 2002: 137-138; id., 2010: 172, fig. 314), en Madinat Ilbīra vidriadas (CANO, 1996: 28-29, fig. 4), en el nivel califal de Pechina (CASTILLO y MARTíNEZ, 1993: 110-111 y lám. XIX), etc.

Sin embargo, no hallamos aquellos jarros con perfil de saco, vidriados y con decoración incisa y excisa, que Gutiérrez sistematizó como la serie V23 a partir de los ejemplares de San Nicolás (Fig. 16, 3-4) (NAVARRO, 1986: 158159, no 340-344; id., 1990: 39, fig. 7.8 a 7.11; NAVARRO y GARCÍA 1989: 259-260, fig. 7.8 a 7.11; GUTIÉRREZ, 1996a: 132-133). Aunque fueron datados en la segunda mitad del siglo IX debido a que se los consideró similares a los ejemplares emirales de Pechina, es necesario destacar que sus paralelos más cercanos se hallan efectivamente en la madina almeriense, pero en el nivel califal ${ }^{20}$. Independientemen-

18. Hay que apuntar que en el nivel antiguo de Pechina se documentaron abundantes redomas con pitorro, si bien con formas distintas a la que nos ocupa (CASTILLO y MARTíNEZ, 1993: 92-93, Lám. IX.3).

19. Relación que ya fue destacada por Rafael Azuar (1989b: 308). Así, un ejemplar del ribāt de Guardamar (MENÉNDEZ, 2004: fig. 56) y otro del Castellar de Alcoy (PÉREZ BOTÍ, 2014: 59-60 y fig. 6): ambos son de manufactura relativamente tosca y presentan el cuerpo decorado con pincel fino, con representaciones en el cuello de flores de loto entre metopas, motivo que ha aparecido en las producciones de un alfar de Elche (AZUAR y MENÉNDEZ, 1999) y otro de Murcia (MUÑOZ y CASTAÑO, 1993). También con franjas verticales rellenas de líneas ondulantes se decora un aguamanil procedente del Sotanillo (Alicante) (http://www.marqalicante. com/Paginas/es/PIEZA-DEL-MES-Aguamanil-P549-M1.html).

20. Los ejemplares de ese nivel alcanzan capacidades similares a los murcianos, mientras que todos los emirales salvo uno presentan un volumen entre medio y un litro. Ésta es la capacidad de otros ejemplares del siglo IX, como el aparecido en el Tolmo de Minateda, medidas tomadas sobre los dibujos de Castillo y Martínez (1993: 88 y 109, láms. VI y XVIII) y Gutiérrez (2011: 204, fig. 5.7). 
te de la cronología, lo que sí manifiesta con claridad la calle Pascual, confirmado por Belluga, es que se trata de una serie poco representada.

La cerámica de cocina, 185 fragmentos que suponen poco más de un cuarto del total, no varía demasiado con respecto a la de los niveles anteriores de la calle Pascual, aunque ahora tenemos marmitas completas que nos permiten observar las variantes formales: de hombro alto (Fig. 13, 2110-30); de perfil troncocónico sencillo (Fig. 13, 2101-64), además de otra de pequeño tamaño (Fig. 13, 1930-8). La decoración incisa tiende a ser horizontal o levemente ondulada, características similares a las que observamos en el alfar de San Nicolás (Fig. 16, 24-25) (NAVARRO, 1990: fig. 8). No se detecta la olla de cuello y borde engrosado al exterior, con asas de cinta desde el labio al hombro, lo que podría entenderse como un indicador de relativa antigüedad, ya que Gutiérrez señaló que este tipo, al que llama M5, aparece en contextos de la segunda mitad del X y comienzos del XI coexistiendo con el anterior y sustituyéndolo paulatinamente (GUTIÉRREZ, 1996a: 79-80). De hecho, en el ribāt de Guardamar no aparece en la fase anterior al 944 pero sí en la siguiente, aunque aún de forma muy minoritaria (MENÉNDEZ, 2004: 111-114). No se encuentra entre los recipientes de cocina publicados del alfar de San Nicolás (NAVARRO, 1990: 40-41, fig. 8), ni tampoco en la reocupación islámica de la basílica de Algezares (Murcia) (NAVARRO, 1986: 132 y 133), que puede fecharse entre la segunda

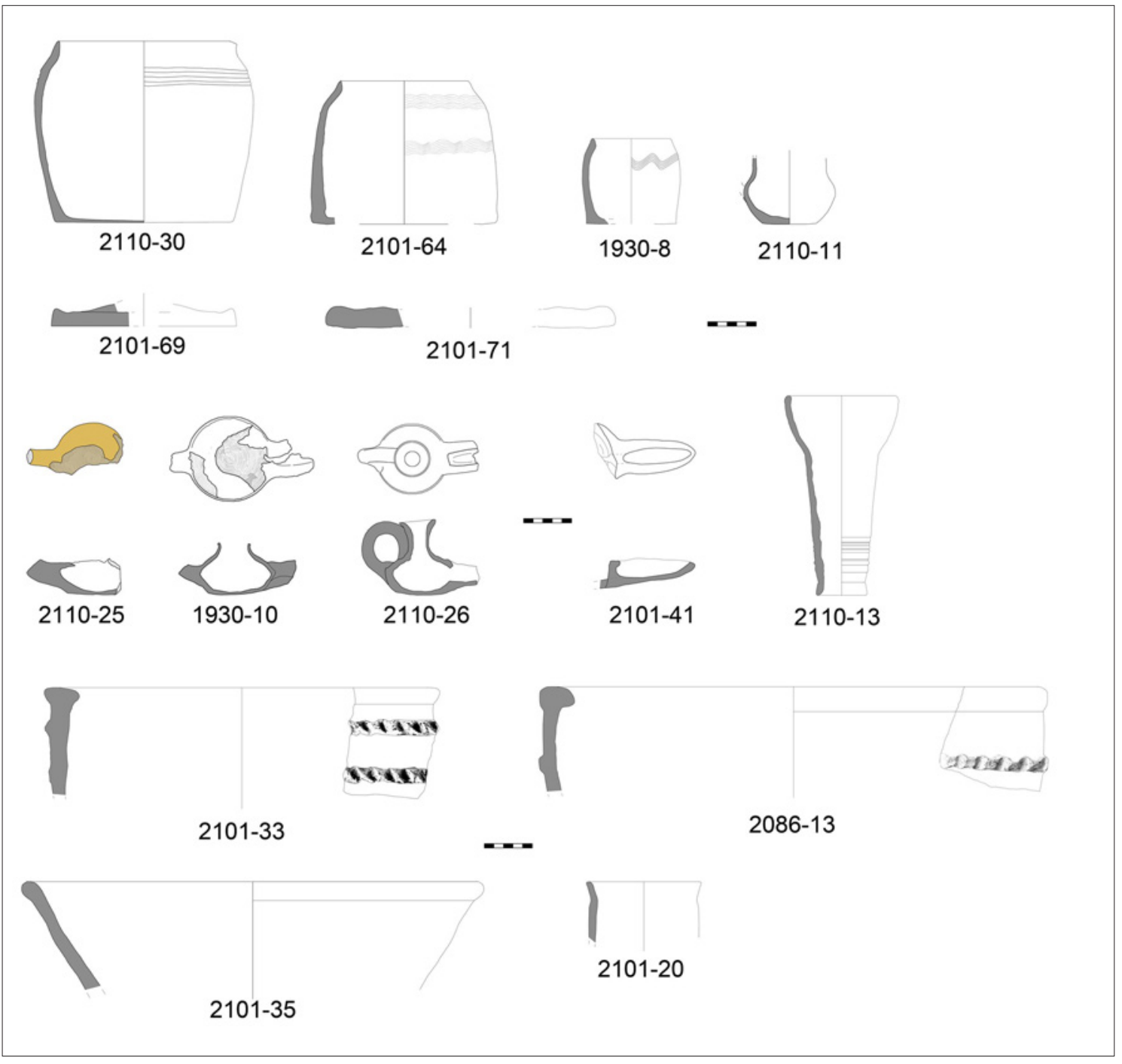

Fig. 13. Cerámica de la Fase V. Cerámicas de cocina, usos múltiples, contenedores de fuego, etc. 
mitad del IX y la primera del X (GUTIÉRREZ, 1996a: 349). Tampoco está entre el material encontrado en un horno de Lorca arrasado a mediados del siglo X (MARTíNEZ y PONCE, 1995a: 147 y 153). Sí aparece, sin embargo, en el nivel III de calle Fuensanta, el previo a la construcción del palacio, del que se ha destacado su semejanza en muchos aspectos con el conjunto de San Nicolás (BERNABÉ y LÓPEZ, 1993: 44, fig. 20).

Las tapaderas, en total 10 fragmentos, son planas, muy similares a las de la fase anterior, aunque parecen tener un diámetro menor (Fig. 13, 2101-69) y aparece una forma de mayor tamaño sin la pestaña del borde ni las digitaciones sobre él (Fig. 13, 2101-71). Existen varios alcadafes, de grandes dimensiones y relativamente profundos, con refuerzos ungulados y bordes almendrados (Fig. 13, 2101-33 y 2086-13), equivalentes al tipo $V$ de Madinat al-Zahrā' (VALLEJO y ESCUDERO, 1996: 141, 164 y Fig. 29) y a la forma M29.2 de la clasificación de Sonia Gutiérrez que ella denomina como barreños (1996a: 94, fig. 28). También hay un ejemplar de perfil troncocónico invertido que respondería al tipo de alcadafe o lebrillo que tendrá una amplia presencia en los contextos andalusíes posteriores (Fig. 13, 2101-35); en otros puntos de Murcia, concretamente en el alfar de San Nicolás y en el número 6 de esa misma calle se han hallado piezas similares en contextos, probablemente, del siglo X, según recoge Gutiérrez (1996a: 93 y 94, forma M28.1). Los candiles muestran también algunas variantes con respecto a los de las fases previas: la piquera es proporcionalmente mayor, o la cazoleta menor, y ésta última presenta un perfil algo más carenado. Además, la ejecución en general es más cuidada. Documentamos algún tannur u hornillo in situ, pero en un lamentable estado de con- servación. Finalmente hay que hacer mención a la presencia de un atabal (Fig. 13, 2110-13) y un posible atanor o tubo (Fig. 13, 2101-20), aunque tenemos algunas dudas acerca de la catalogación de este último.

Los ataifores (Fig. 14) decorados en verde y manganeso presentan cubiertas vítreas muy degradadas ${ }^{21}$ y los fondos son generalmente melados o blancos. Son mayoritariamente de base plana, el tipo más abundante en Madinat al-Zahrā' (ESCUDERO, 1988-1990: 134; CANO, 1996: 13 y 48); los pies anulares, siempre bajos y anchos, son menos frecuentes. Entre los hallados en el relleno de la fosa (fase Va), el ataifor 2101-4 (Fig. 14) se asemeja a los de perfil sinuoso con origen en prototipos orientales, que en al-Andalus aparecen asociados a la decoración en verde y manganeso desde el califato (ZOZAYA, 1980b: 313; ESCUDERO, 1988-1990: 142). Aunque ostenta esta decoración y posiblemente representaba un tema figurativo, quizás un ave, el fondo no es blanco sino traslúcido o ligeramente melado. La pieza 2101-8 (Fig. 14), a la que quizás se pudiera asociar el anillo de solero 2101-7 (Fig. 14), presenta un perfil con carena poco marcada situada en la zona baja y su cubierta está sumamente degradada, pero se observan trazos en manganeso y una superficie blanca ${ }^{22}$. En el nivel de la fase $\mathrm{Vb}$ apareció un fragmento con decoración de verde y manganeso, que destaca por su buen estado de conservación y el espesor del esmalte tanto al interior como al exterior (Fig. 14, 1822-1). En relación a la última fase (Vc) documentamos varias piezas de características análogas a las comentadas, como un fragmento de borde engrosado al exterior con sección circular y vedrío degradado (Fig. 14, 1793-4) que anuncia los labios más frecuentes en los ataifores de época taifa. Los perfiles de los ataifores muestran grandes semejanzas

21. Representados en las tablas por un color marrón grisáceo. El total de ataifores es de 46 fragmentos, el 6,36\% de las piezas; de ellos sólo 7 con seguridad están decorados en verde y manganeso, siendo el resto otras decoraciones o bien frustrados.

22. Gómez Moreno efectuó la descripción clásica de la técnica decorativa del verde y manganeso a partir de los materiales de Madīnat Ilbîra (Granada); según este autor, el fondo blanco se conseguiría con una engalba blanca que estaría recubierta de un baño de plomo, de manera que no sería preciso el uso de estaño (GÓMEZ-MORENO, 1951: 311). Los análisis, sin embargo, han desmentido este proceso, atribuyendo la capa polvorienta blanca que en ocasiones se observa a la degradación del propio esmalte (ESCUDERO, 1988-1990: 135; GONZÁLEZ et al., 1992; PICON, THIRIOT y VALLAURI, 1995: 45). 


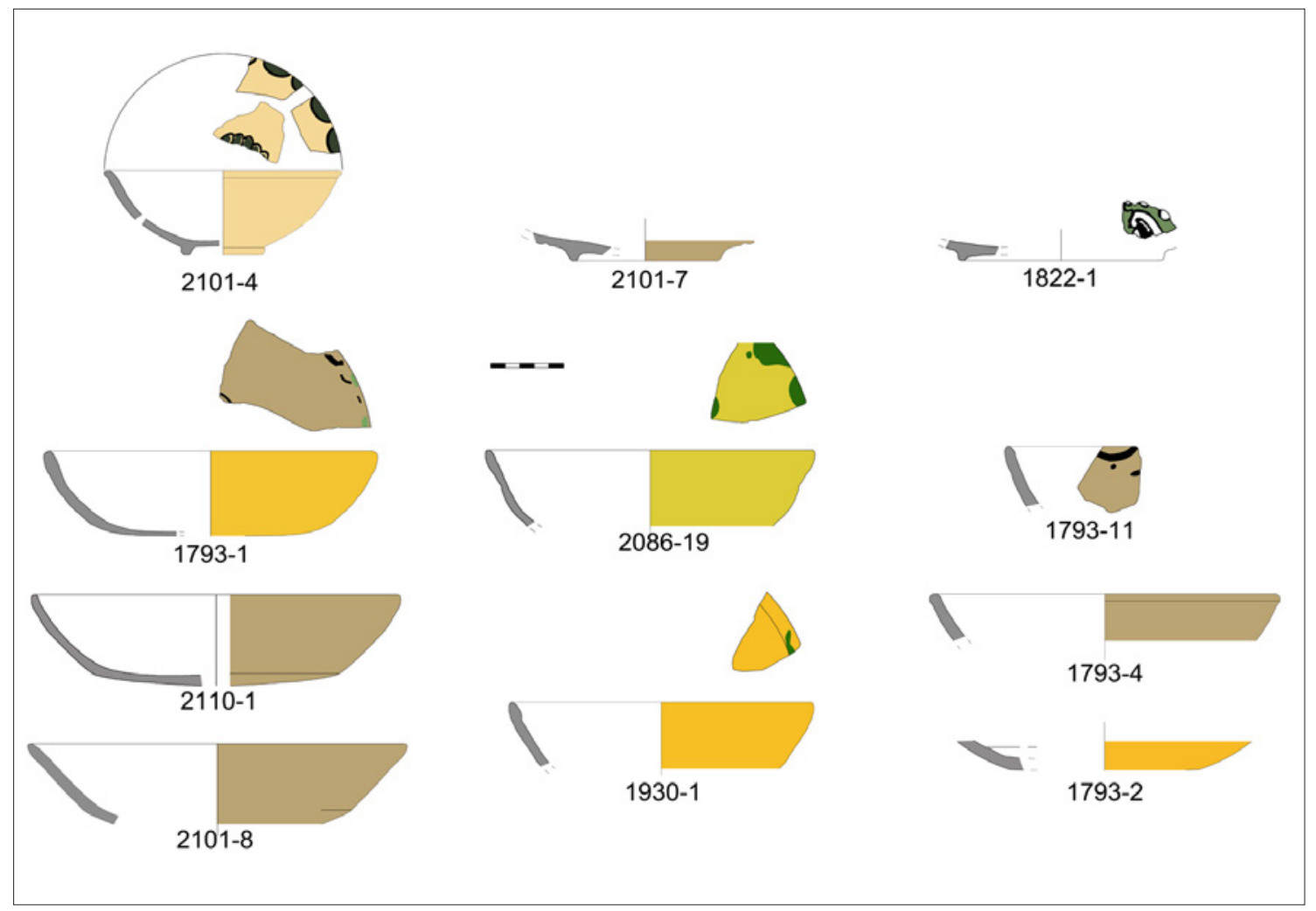

Fig. 14. Cerámica de la Fase V. Ataifores.

con los de otros conjuntos tardo-califales, como los de Madinat al-Zahrā' (ESCUDERO, 1988-1990: 128-129, 140-143) o los del nivel Il de Pechina, en donde se encuentran tanto los de base plana como los de pie anular bajo y ancho, con perfil hemiesférico y con borde exvasado o simple y también carenados (CASTILLO y MARTÍNEZ, 1993: 103 y 108). En cuanto a los aspectos decorativos, lo más destacado es la presencia generalizada de la decoración vidriada policroma, principalmente sobre formas abiertas. Por desgracia, el conjunto en general es reducido y, además, una proporción relativamente alta de los fragmentos vidriados presentan la superficie tan degradada que no es posible identificar la técnica. No obstante, hemos podido catalogar en el conjunto ahora estudiado cuatro combinaciones: $1^{\text {a }}$ motivo en verde y manganeso sobre fondo blanco; $2^{a}$ verde y manganeso sobre fondo melado; $3^{a}$ manganeso sobre fondo melado y $4^{a}$ verde sobre fondo melado.

Hasta fechas recientes parte de la bibliografía sigue manteniendo en lo básico la hipótesis inédita de Manuel Ocaña de una vinculación entre el verde y manganeso y el Estado califal cordobés. La construcción de Madinnat al-Zahrā' (ca. 939) marcaría el inicio de la producción en ese lugar, expandiéndose con características estilísticas y formales diversas durante la misma época califal, alcanzando su cénit durante las taifas del siglo XI (ROSSELLÓ, 1987: 126 y 127; id., 2002: 181; ESCUDERO, 1988-1990: 137 y 138; BARCELÓ, 1993; CANO, 1996: 45-48). Entre los hallazgos que corroboran la presencia de verde y manganeso en época califal temprana fuera de Córdoba podemos citar un contexto de Mallorca datado a mediados del siglo X, sobre ataifores que presentan ya pie anular (RIERA, 1999: 178; ROSSELLÓ, 2002: 181); así como Pechina, si aceptamos su abandono a partir del 955 (ACIÉN y MARTíNEZ, 1989: 123 y 124; CASTILLO y MARTÍNEZ, 1993: 103, 106-108, lám. XVI-XVII). Sin embargo, cada vez más estudios identifican la existencia de verde y manganeso en contextos anteriores a la construcción de la ciudad palatina e incluso algunos con dataciones emirales, tal y como 
hace años ya indicó Zozaya (1980b: 312) ${ }^{23}$. Este tipo de decoración, por consiguiente, apenas nos aportará mayores precisiones cronológicas al estudio del conjunto, aunque sí permite plantear algún otro aspecto de interés. En general las características que detectamos en los ataifores de la calle Pascual, tanto en las cubiertas como en los perfiles, son las mismas que se documentaron en el alfar de San Nicolás, que producía este tipo de piezas tanto de fondo plano como con incipientes pies anulares, en verde y manganeso sobre blanco y manganeso sobre melado, aunque es necesario destacar que en San Nicolás, según la información de que disponemos, no se hallaron piezas en verde y manganeso sobre fondo melado. A partir de estos datos creemos necesario destacar que, según los datos de la calle Pascual, la extensión del verde y manganeso sería tardía, no anterior a mediados del siglo $X$ y ya probablemente en el último cuarto. También cabe plantear la hipótesis de la existencia de una producción local de piezas bícromas o policromas sobre fondo melado, en la que no se habría extendido el uso del óxido de estaño para crear los fondos blancos, a diferencia de otros centros productores coetáneos.

Otro dato a tener en cuenta es la ausencia de cuerda seca parcial, que en el caso de la calle Pascual no estará presente hasta los niveles claramente taifas de la fase VI. Aunque el origen de esta técnica puede remontarse al siglo VIII en Siria y al Iraq del siglo IX (WATSON, 2014: 129), en al-Andalus parece que no se puede fechar antes de la segunda mitad del siglo X (DÉLÉRY, 2006) ${ }^{24}$. En Murcia podría tener una datación similar, dado que se hallaron piezas en los niveles del solar del alfar de S. Nicolás situados a la misma cota que el testar y por debajo de los suelos de trabajo de la casa que amortizó el establecimiento alfarero, aunque no aparecieron en la propia bolsada del testar (NAVARRO, 1990: 36). En el nivel previo al palacio de la calle Fuensanta de Murcia, datado por sus excavadores a mediados del siglo X, ya está representada, no así en los anteriores (BERNABÉ y LÓPEZ, 1993: 46). En resumen, la presencia de la técnica decorativa de la cuerda seca en alAndalus posiblemente se pueda remontar a la segunda mitad del siglo $X$, aunque en esa fecha sería muy excepcional; su generalización parece que debió de producirse en el siglo XI. Por consiguiente, la ausencia de cuerda seca parcial en el conjunto que examinamos es una evidencia de relativa antigüedad.

Finalmente hay que apuntar que las decoraciones de las fases anteriores sobre formas cerradas pequeñas o medianas, de finas líneas horizontales o filetes, son ya esporádicas y solo se han conservado unos pocos

23. La propia Córdoba ha deparado el hallazgo de un pozo ciego de cronología emiral final con piezas decoradas en verde y manganeso, aunque de características particulares que lo diferencian de la producción "clásica" posterior (SALINAS, 2013) A partir del estudio de la estratigrafía del arrabal de Cercadilla se considera que el verde y manganeso hace su aparición en los contextos de finales del siglo IX y comienzos del X, quizás en los primeros años del último siglo (FUERTES, 2010, p. 196) Es el caso de Marroquíes Bajos en Jaén, en donde se ha documentado verde manganeso en contextos emirales, aunque la difusión masiva se diera en el califato (PÉREZ ALVARADO et al., 2003: 77) También en la alcazaba de Madīnat Ilbīra, que se abandonaría en el primer cuarto del siglo X, han aparecido piezas con esa decoración (CARVAJAL, 2008: 247-248, 286-288) Además hay que recordar que los aglabíes de Raqqāda (Kairouan, Túnez) en el último cuarto del siglo IX producían verde y manganeso (DAOULATLI, 1995; BEN AMARA et al., 2001). De esta procedencia serían dos ejemplares hallados en Tudmīr: un ataifor del teatro romano de Cartagena que aparece en la amortización de los niveles emirales; y una pieza procedente de un nivel de la primera mitad del siglo X de la calle Fuensanta de Murcia, con fondo melado y motivos en verde y manganeso (BERNABÉ y LÓPEZ, 1993: fig. 15.1) una decoración inusual en la producción clásica atribuida a Madīnat al-Zahrā' y/o Madinat Ilbīra. Procedan o no de Túnez, parecen remitir a una cronología relativamente temprana, cuando el fondo melado es característico y aún no se representan los temas decorativos que serán habituales (SS. VIII-IX). Sin embargo, la cronología del siglo VIII que se ha dado a varios ataifores de Silves (Portugal) a partir de análisis de carbono 14 nos parece difícil de admitir (GOMES, 1992: 19-32).

24. En Madīnat al-Zahrā' se encontraron piezas de cuerda seca parcial que fueron en principio atribuidas al califato; tras su revisión se ha concluido que muchas de ellas datarían de época almohade y serían fruto de una reocupación de la ciudad palatina, pero para otras se mantiene una datación califal (DÉLÉRY, 2006: 1493-1517) En Cercadilla (Córdoba) se estima que aparece en los últimos años del califato, si bien en proporciones muy escasas (FUERTES, 2010: 196, 233, 265; FUERTES, 2002: 203, 232, Gráfico 4) En el ribāt de Guardamar aparece en los contextos de abandono, que se datan entre fines del siglo X y primera mitad del XI, pero está ausente en el nivel prefundacional. Igualmente, en Pechina se documenta en el nivel califal y en Almería aparecieron varias piezas fechadas a mediados del siglo X, si bien el conjunto presenta características generales bastante más avanzadas que las del ajuar de la fosa de la calle Pascual (DOMínGUEZ, MUÑOZ y RAMOS, 1987: 570, 571 y 576). 


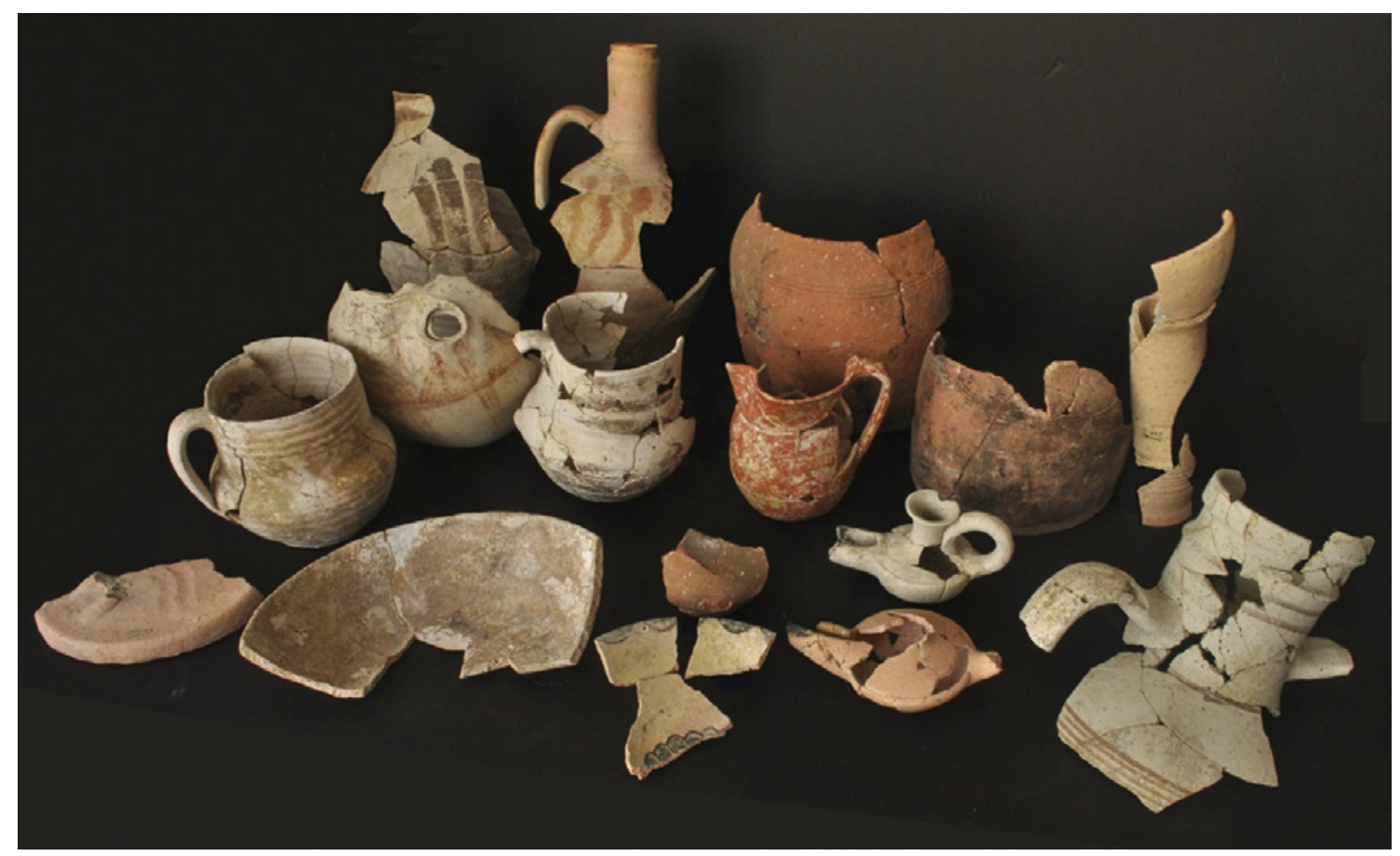

Fig. 15. Conjunto de cerámicas de la fase V.

fragmentos así ornamentados. Fuera de esto, sin embargo, veremos que se dará sobre contenedores mayores, las jarras, pero por lo general con un color vinoso. Sí se conservan las decoraciones más complejas, de triángulos reticulados y ondulaciones verticales.

En conclusión, para fechar el conjunto de materiales que hemos examinado carecemos de elementos que nos permitan obtener una datación absoluta, pero sí contamos con otras fuentes de información, como la cronología relativa y la comparación tipológica con materiales procedentes de otros yacimientos, a partir de todo lo cual se puede situar este conjunto de cerámicas entre el último cuarto del siglo X y mediados del siglo XI.

\section{Conclusiones}

La fase más antigua documentada en calle Pascual, de la que conocemos muy poco, abarca una potencia estratigráfica de $2 \mathrm{~m}$ y consta de distintos niveles, del inferior de los cuales procede la mayor parte de la cerámica (fase I, Fig. 3). Sobre ella se desarrolló una acti- vidad alfarera que dio lugar a la excavación de una gran fosa, luego colmatada, así como la perforación de una barrera de extracción y su amortización, momento del cual obtenemos la cerámica de la segunda fase (fase II, Figs. 4 y 5). Esta actividad quedó sellada por el establecimiento de una cocina que perduró el suficiente tiempo para que se realizaran reformas en los muros, se elevaran los niveles de circulación y se superpusieran tannures y hogares (fase III, Figs. 6-8). Fue amortizada por una nueva cocina que, si bien no nos ha aportado muchos materiales, sí que evidencia una reestructuración de la superficie con nuevas orientaciones en las estancias (fase IV, Figs. 6 y 8). Toda esta secuencia está rota por una fosa que proporciona el primer registro califal avanzado (fase V, Figs. 9 y 11-15), con cerámicas decoradas en verde y manganeso, asociado a una nueva remodelación de la zona que supuso la implantación de otra cocina.

En nuestra opinión, es posible ubicar esta estratigrafía en el intervalo correspondiente a la época emiral, que en Murcia arranca a partir de su fundación oficial en el 825, y el final del periodo califal. Así, los niveles más antiguos 
(Fases I y II) se remontarían al segundo cuarto del siglo IX con una actividad indeterminada pero que evidencia un ambiente súbitamente antropizado; no se trata de una zona con edificaciones, pero sí que debió de estar próxima al caserío porque registramos manifestaciones típicas de carácter periurbano hasta el establecimiento de las actividades alfareras. Entre el último cuarto de siglo y comienzos del siguiente se implantan estructuras domésticas, concretamente una cocina, cuya primera fase será amortizada creemos que hacia el segundo cuarto del siglo X o a lo sumo en el tercero. Posteriormente se llevan a cabo reformas y la construcción de una nueva cocina que a su vez se abandona en la segunda mitad del siglo X, quizás en el último cuarto de siglo.

Hasta la excavación de calle Pascual, en la ciudad de Murcia no se habían identificado los niveles emirales y así, en un solar excavado a unos 100 m, en la calle San Pedro (GALLEGO y RAMÍREZ, 1993), se halló un conjunto de cerámicas que fueron datadas en época califal, sin duda por la similitud de los jarritos con los de San Nicolás, aunque en general son piezas muy parecida a las de nuestra fase III que nosotros hoy nos inclinaríamos por datar en la primera mitad del X. También en la calle Fuensanta, cerca del alcázar, se excavó una gran casa que se fechó en época califal, bajo la cual se halló un nivel de ocupación anterior que a su vez amortizaba un estrato con cerámicas que se dataron "en un momento anterior a la mitad del siglo X" (BERNABÉ y LÓPEZ, 1993: 40-43).

En resumen, de esta primera aproximación a la cerámica emiral de Murcia a partir de los materiales de calle Pascual parece deducirse que desde el inicio predominan los rasgos plenamente islámicos, como los jarritos, las marmitas de base plana, los cangilones, los tannures o la decoración a base de filetes pintados a la almagra, mientras que los tipos de herencia visigoda están prácticamente ausentes, como sucede por ejemplo con las ollas que, sin embargo, abundan en otros yacimientos como el Tolmo de Minateda y Jaén. Todo ello parece confirmar que Murcia así como Bayyāna y otras medinas costeras que funcionan como cabezas de puente del régimen omeya en las provincias, se habrían constituido en "agentes islamizadores" a través de la práctica urbana y la actividad comercial (ACIÉN, 1993: 167). La relevancia de estas ciudades en la segunda mitad del siglo IX se incrementó por su lealtad al Estado cordobés finalmente triunfante, durante las graves y recurrentes insurrecciones que precedieron a la proclamación del califato. Especialmente en el caso de aquellas que constituían auténticos bastiones fieles a Córdoba en medio de territorios levantiscos, como Málaga, en donde ese alineamiento político se vio acompañado de un notable desarrollo industrial, en concreto alfares que producían piezas vidriadas para consumo interno y exportación. Manuel Acién y otros colegas llamaban la atención sobre "la presencia masiva de estas cerámicas en ciudades consolidadas dentro del concepto urbano islámico, como Pechina, Málaga o Murcia, en contraposición a asentamientos no urbanos" (ACIÉN, CASTAÑO, NAVARRO, SALADO y VERA, 2003: 432 y 433); por tanto, según estos investigadores, Murcia estaría entre las ciudades que contribuyeron a la afirmación política, social y cultural del Estado omeya en provincias. Inicialmente Sonia Gutiérrez planteaba el tema de manera similar al indicar que las piezas vidriadas de la segunda mitad del siglo IX serían procedentes de núcleos urbanos que comenzaban a estructurar sus mercados, como Pechina y Murcia (GUTIÉRREZ, 1999: 178); sin embargo, posteriormente parece excluir a esta ciudad del grupo de "agentes islamizadores" durante época emiral, suponiendo un origen andaluz para los vidriados de Tudmîr: "En siglo IX los territorios periféricos del oriente de Al-Andalus comienzan a integrarse en los circuitos comerciales de carácter suprarregional, vinculados en este caso a los centros productores de Andalucía Oriental, como Málaga o Pechina, de donde proceden los vidriados que llegan a Tudmir, sin que se detecte una influencia cordobesa significativa; solo más tarde, ya en el siglo X, la influencia de la ciudad de Murcia se hace patente y la uniformidad de los ajuares, incluidos los culinarios, denota por fin un medio social homogéneamente islamizado y una organización de mercado consolidada" 
(ALBA y GUTIÉRREZ, 2008: 607). No obstante, la información proporcionada por calle Pascual, confirmaría la relevancia socioeconómica de Murcia entre finales del siglo IX y comienzos del $X$, lo que por otro lado conviene con su carácter de capital oficial del sureste, sede del ejército y del aparato estatal omeya delegado en la provincia. Es más, la presencia de una gran fosa para la acumulación de arcillas, con función probablemente de pudridero, correspondiente a la fase II (segunda mitad del siglo IX), así como los indicios de actividad alfarera temprana en el solar próximo de calle San Pedro a que hemos hecho referencia, parecen indicar que desde el siglo IX se está produciendo cerámica en la ciudad de Murcia, de lo que cabría deducir que la ciudad desempeñó un papel activo en el proceso de islamización, no sólo política sino también cultural y comercial, como expresaría materialmente la cerámica.

De la fase $V$ de calle Pascual hay que destacar la homogeneidad tipológica del conjunto cerámico, prueba de que se formó en un lapso de tiempo reducido, lo que conviene con las características del hallazgo pues en su mayor parte está compuesto por piezas completas desechadas en el interior de una fosa. Entre los tipos de mesa siguen siendo mayoritarias las bases planas de los ataifores con bordes simples, y las formas cerradas corresponden siempre a jarritos y jarros, sin que haga clara aparición aún la jarrita. Entre los jarritos hay que resaltar la continuidad y abundancia del

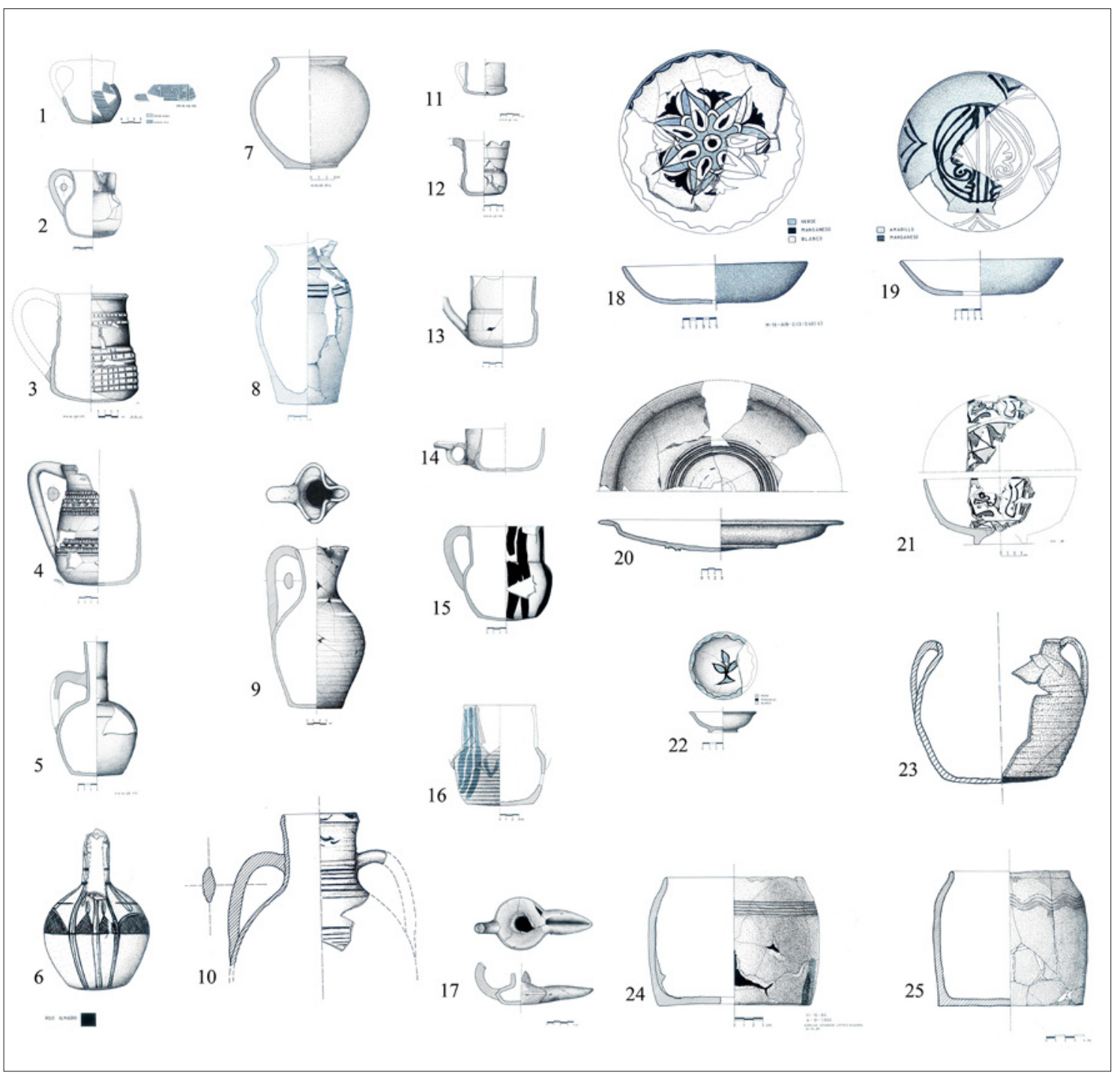

Fig. 16. Selección de piezas del testar A-B de San Nicolás (Murcia), a partir de la documentación facilitada por J. Navarro Palazón. 
tipo de pequeño tamaño y galbo cilíndrico, tan característico de los contextos emirales. Hay que destacar la ausencia de la técnica de cuerda seca, en cualquiera de sus dos variantes, pero sí la presencia de verde y manganeso sobre formas abiertas. Observamos en el ajuar algunos rasgos de relativa antigüedad pues en el contexto geográfico próximo se detecta la evolución de ciertas formas como la aparición de las marmitas con cuello y borde engrosado y la sustitución progresiva de los jarritos por las jarritas. En el nivel $V$ de calle Pascual no aparecen los nuevos tipos y sí los antiguos, aunque dentro de un contexto general similar a los ajuares clásicos de época califal tardía como al-Zahrā', Ilbīra, niveles recientes de Pechina y Guardamar; y, en Murcia, al alfar de S. Nicolás y al nivel III de calle Fuensanta. De todos ellos, las cronologías más fiables las ofrecen Ilbīra, al-Zahrā' y Pechina, dadas las referencias en las fuentes escritas a su abandono, y los tres coinciden en una fecha del primer cuarto del siglo XI. Por tanto, creemos que se puede concretar la datación de los materiales de esta fase $V$ entre el último cuarto del siglo $X$ y primer cuarto del siglo XI, una fecha que queda dentro de la horquilla que nos aportaba la cronología relativa obtenida a partir del análisis estratigráfico de esta excavación.

Estamos, por tanto, ante el ajuar correspondiente a un momento que se sitúa entre la estabilidad política del califato pleno, la fitna o guerra civil y la volatilidad de los reinos de taifas que lo sucedieron. Atendiendo a la economía, el periodo que se inicia en el $X$ y abarca hasta el XIV se caracteriza en Europa occidental, en términos generales, por un considerable aumento de la población, una expansión de las tierras de cultivo, un cierto progreso técnico y un notable incremento de la producción para el mercado (HILTON, 1985: 15-17 y ss). A pesar de los disturbios ocasionados por la fitna, el siglo XI representa en al-Andalus el apogeo de las ciudades, centros de poder, en donde se concentra la cultura y desde donde se controla económicamente su territorio (MAZZOLI-GUINTARD, 1996: 187). En el sureste peninsular, la prosperidad urbana parece asociarse al proceso de comercialización agrícola que originó el enriquecimiento de unos aristócratas terratenientes que moraban en la ciudad, gracias a lo cual emprendieron gastos suntuarios que crearon la demanda que dio lugar a la expansión del artesanado, lo que a su vez atrajo a los núcleos urbanos a una población campesina desposeída por la expansión de las élites en el campo (JIMÉNEZ, 2016). La evidencia más notable del proceso de comercialización a que hacíamos referencia es la aparición y difusión de las cerámicas decoradas en verdey manganeso, que estaban ausentes en los niveles previos de la secuencia estratigráfica de calle Pascual que venimos examinando. Estas piezas se producían en Murcia, como lo demuestran los desechos del alfar de San Nicolás, establecimiento artesanal que debemos considerar contemporáneo del ajuar que hemos examinando en este trabajo a juzgar por las múltiples similitudes técnicas, formales y decorativas. Las producciones de estos talleres se consumían en el medio doméstico urbano, según demuestra calle Pascual, pero también se extendieron rápida y profusamente por ámbitos rurales como prueba de un intercambio intenso y la presencia de un campesinado que producía los excedentes comercializables que requería para el pago de impuestos y también para la adquisición de ciertos bienes manufacturados en las ciudades. En este sentido cabe interpretar también la especialización de los talleres alfareros en ciertas producciones y su estandarización, como parece suceder con los jarritos y los grandes jarros decorados que conocemos bien gracias a S. Nicolás y que, sin embargo, apenas están representados en otros contextos urbanos de Murcia, como el que nos ocupa o el de Belluga, lo que sugiere una producción fuertemente orientada al comercio exterior.

\section{BIBLIOGRAFÍA}

ACIÉN ALMANSA, A. (1993): "La cultura material de época emiral en el sur de al-Andalus. Nuevas perspectivas", La cerámica medieval en el sur de al-Andalus, Granada, pp. 153-172.

ACIÉN ALMANSA, M. y MARTÍNEZ MADRID, R. (1989): "Cerámica islámica arcaica del sureste de al-Andalus", Boletín de Arqueología Medieval, 3, pp. 123-135. 
ACIÉN ALMANSA, M.; CASTILLO GALDEANO, F. y MARTÍNEZ MADRID, R. (1990): "Excavación de un barrio artesanal de Baŷȳāna”, Archéologie Islamique, 1, pp. 147-168.

ACIÉN ALMANSA, M., et al. (1991): "Evolución de los tipos cerámicos en el S.E. de Al-Andalus", V Colloque International sur la céramique médiévale en Méditerranée Occidentale, Rabat, pp. 125-129.

ACIÉN ALMANSA, M.; CASTAÑO AGUILAR, J. M.; NAVARRO LUENGO, I.; SALADO ESCAÑO, J. B. y VERA REINA, M. (2003): "Cerámicas tardorromanas y altomedievales en Málaga, Ronda y Morón”, Cerámicas tardorromanas y altomedievales en la Península Ibérica. Anejos del Archivo Español de Arqueología, XXVIII (II Simposio de Arqueología. Mérida 2001), Madrid, pp. 411-454.

ACIÉN ALMANSA, M. y MARTÍNEZ MADRID, R. (1989): "Cerámica islámica arcaica del sureste de al-Andalus", Boletín de Arqueología Medieval, 3, pp. 123-135.

ALBA, M. y FEIJOO, S. (2003): "Pautas evolutivas de la cerámica común de Mérida en épocas visigoda y emiral", Cerámicas tardorromanas y altomedievales en la Península Ibérica, Anejos del Archivo Español de Arqueología, XXVIII (II Simposio de Arqueología. Mérida 2001), Madrid, pp. 483-504.

ALBA CALZADO, M. y GUTIÉRREZ LLORET, S. (2008): "Las producciones de transición al Mundo Islámico: el problema de la cerámica paleoandalusí (siglos VIII y IX)", Cerámicas hispanorromanas. Un estado de la cuestión, Cádiz, pp. 585-613.

AL-'UDRT̄ en SÁNCHEZ MARTÍNEZ, M. (1975-1976): "La cora de Ilbira (Granada y Almería) en los siglos X y XI, según al-'Udrì', Cuadernos de Historia del Islam, 7, pp. 5-82.

AMORÓS RUIZ, V. (2011): Contextos cerámicos del siglo VIII en el Tolmo de Minateda, Albacete.

AMORÓS RUIZ, V. y FILI, A. (2011): "La céramique islamique des niveaux islamiques de Volubilis (Wal'la) d'après les fouilles de la misión maroco-anglaise", La céramique maghrébine du haut moyen age (VIIIe-Xe siècle), Rome, pp. 23-47.

AZUAR RUIZ, R. (1989a): La Rábita califal de las dunas de Guardamar, Alicante.

AZUAR RUIZ, R. (1989b): Denia islámica. Arqueología y poblamiento, Alicante.

AZUAR RUIZ, R. y MENÉNDEZ FUEYO, J.L. (1999): "El alfar islámico de Elche (Alicante) (siglos XI-XIII)", II Congreso de Arqueología Penínsular, vol. 4, Zamora, pp. 679-670.

BARCELÓ PERELLÓ, M. (1993): "Al-Mulk. El verde y el blanco. La vajilla califal omeya de Madînat al-Zahrâ'", La cerámica altomedieval en el sur de al-Andalus, Granada, pp. 291-299.

BATES, M. L. (1981): "The Function of Fatimid and Ayyubid Glass Weights", Journal of the Economic and Social History of the Orient, 24 No. 1, pp. 63-92.

BEN AMARA, A., SCHVOERER, M., DAOULATLI, A., RAMMAH, M. (2001): "Jaune de Raqqada" et autres couleurs de céramiques glaçurées aghlabides de Tunisie (IX - X siècles)", Revue d’Archéométrie, 25, pp. 179-186
BERNABÉ GUILLAMÓN, M. y LÓPEZ MARTÍNEZ, J. D. (1993): El Palacio Islámico de la calle Fuensanta, Murcia.

CANDÓN, A.; GÓMEZ, S.; MACÍAS, S. y RAFAEL, L. (2001): "Mértola en torno al año mil", Actas del V Congreso de Arqueología Medieval Española, 1999, vol. 2, Valladolid, pp. 559-568.

CANO MONTORO, E. (2007): “Formas cerámicas representativas de la ocupación de cuevas naturales, durante la Edad Media andalusí, en el entorno de Madînat Baguh (Priego de Córdoba)", Antiqvitas, 18-19, pp. 141-168.

CANO PIEDRA, C. (1990): "Estudio sistemático de la cerámica de Madinat Ilbiira", Cuadernos de la Alhambra, 26, pp. 25-68.

CANO PIEDRA, C. (1996): La cerámica verde-manganeso de Madinat al-Zahrā', Granada.

CANTO, A. y RETUERCE, M. (1993): "Cerámicas y monedas andalusíes: un modelo de datación en época emiral", Congreso de Arqueología Peninsular, Oporto, pp. 341-350.

CAÑAVATE CASTEJÓN, V.; MELLADO RIVERA, J. A. y SARABIA BAUTISTA, J. (2009): "Uso, residualidad y problemática del siglo VIII en el palacio de época visigoda del Tolmo de Minateda (Hellín, Albacete)", Arqueología y territorio medieval, 16, pp. 9-31.

CARMONA GONZÁLEZ, A. (2014): "La ciudad de Tudmîr", eHumanista/IVITRA, 5, pp. 392-405.

CARVAJAL LÓPEZ, J. C. (2008): La cerámica de Madinat Ilbira (Atarfe) y el poblamiento altomedieval de la vega de Granada, Granada.

CASAL, Ma. T.; CASTRO, E.; LÓPEZ, R. y SALINAS, E. (2005): "Aproximación al estudio de la cerámica emiral del arrabal de Šaqunda (Qurțuba, Córdoba)", Arqueología y territorio medieval, 12.2, pp. 189-235.

CASTILLO GALDEANO, F. y MARTÍNEZ MADRID, R. (1991): "Estudio de los materiales cerámicos de Baŷȳāna (Pechina, Almería)", Anuario Arqueológico de Andalucía, T-II, Actividades Sistemáticas, Sevilla, pp. 63-72.

CASTILLO GALDEANO, F. y MARTÍNEZ MADRID, R. (1993): "Producciones cerámicas en Baŷȳāna", La cerámica medieval en el sur de al-Andalus, Granada, pp. 68-116.

DAOULATLI, A. (1995): "La production vert et brun en Tunisie du IXe au XIle siècle. Étude historique et stylistique", Le vert \& le brun, Marsella, pp. 68-89.

DÉLÉRY, C. (2006): Dynamiques économiques, sociales et culturelles d'al-Andalus à partir d'une étude de la céramique de cuerda seca (seconde moitié du Xe siècle-première moitié du XIIle siècle), Thèse de doctorat soutenue à l'Université de Toulouse-Le Mirail (sous la direction de Christophe Picard).

DOMÍNGUEZ BEDMAR, M.; MUÑOZ MARÍN, Ma M. y RAMOS DÍAZ, J. R. (1987): "Madinnat al Mariyya. Estudio preliminar de las cerámicas aparecidas en sus atarazanas", / Congreso de Arqueología Medieval Española, T. II, Madrid, pp. 568-577.

ESCUDERO ARANDA, J. (1988-1990): "La cerámica decorada en 'verde y manganeso' de Madinat al-Zahra" Cuadernos de Madinat al-Zahrā', 2, pp. 127-155. 
FERNÁNDEZ-PUERTAS, A. (2009): Mezquita de Córdoba. Su estudio arqueológico, Granada.

FENTRESS, E.; LIMANE, H. (2010): "Excavations in medieval settlements at Volubilis. 2000-2004". Cuadernos de Madinat al-Zahrā, 7, pp. 105-122

FUERTES SANTOS, Ma C. (2002): La cerámica califal del yacimiento de Cercadilla, Córdoba, Sevilla.

FUERTES SANTOS, Ma C. (2010): La cerámica medieval de Cercadilla, Córdoba. Tipología, decoración y función, Sevilla.

GALLEGO GALLARDO, J. y RAMÍREZ SEGURA, E. (1993): "Memoria de las excavaciones realizadas en C/ San Pedro, núm. 21 (Murcia-1989)", Memorias de Arqueología 4. 1989, Murcia, pp. 382-387.

GÓMEZ, S. (2004): La cerámica islámica de Mértola: producción y comercio, Memoria para optar al grado de doctor, Madrid.

GÓMEZ-MORENO MARTíNEZ, M. (1951): Ars Hispaniae. El arte árabe español hasta los almohades. Arte mozárabe, tomo III, Madrid.

GÓMEZ-PACCARD, M., OSETE, Ma L., CHAUVIN, A., PAVÓNCARRASCO, F. J., PÉREZ-ASENSIO, M., JIMÉNEZ, P. y LANOS, Ph. (2016): "New constraints on the most significant paleointensity change in Western Europe over the last two millennia. A non-dipolar origin?", Earth and Planetary Science Letters, 454, pp. 55-64.

GONZÁLEZ GARCÍA, F., GONZÁLEZ RODRÍGUEZ, M., GONZÁLEZ VÍLCHEZ, C. y VALLEJO TRIANO, A. (1992): "Estudio arqueométrico de algunas cerámicas medievales de Madinat al-Zahrā' (Córdoba)", Boletín de la Sociedad Española de Cerámica y Vidrio, vol. 31, n 6, pp. 491-498.

GUTIÉRREZ LLORET, S. (1986): "Cerámicas comunes altomedievales: contribución al estudio del tránsito de la Antigüedad al mundo paleoislámico en las comarcas meridionales del País Valenciano", Lvcentum, 5, pp. 147-167.

GUTIÉRREZ LLORET, S. (1996a): La cora de Tudmîr. De la Antigüedad tardía al mundo islámico, Madrid-Alicante.

GUTIÉRREZ LLORET, S. (1996b): "El aprovechamiento agrícola de las zonas húmedas: la introducción del arcaduz en el sureste de Al-Andalus (siglos VIII y IX)", Arqueología y territorio medieval, 3, pp. 7-19.

GUTIÉRREZ LLORET, S. (1999): "La cerámica emiral de Madinat lyih (el Tolmo de Minateda, Hellín, Albacete): Una primera aproximación", Arqueología y territorio medieval, 6, pp. 71-112.

GUTIÉRREZ LLORET, S. (2004): "El ribāt antes del ribāt", El ribāt califal. Excavaciones e investigaciones (1984-1992), Madrid, pp. 73-87.

GUTIÉRREZ LLORET, S. (2007): "La islamización de Tudmîr: balance y perspectivas", Villa II. Villes et campagnes de Tarraconaise et d'al-Andalus (Vle-Xle siècle): la transition, Méridiennes, 'Études Médiévales Ibériques', Toulouse, pp. 275-318.
GUTIÉRREZ LLORET, S. (2011): "El reconocimiento arqueológico de la islamización. Una mirada desde alAndalus", 711. Arqueología e historia entre dos mundos. Vol. I, Alcalá de Henares, pp. 189-210.

GUTIÉRREZ LLORET, S. (2014): "La materialidad del Pacto de Teodomiro a la luz de la arqueología", eHumanista/ IVITRA, 5, pp. 262-288.

GUTIÉRREZ LLORET, S., GAMO PARRAS, B., AMORÓS RUIZ, V. (2003): "Los contextos cerámicos altomedievales del Tolmo de Minateda y la cerámica altomedieval en el sudeste de la Península Ibérica", Cerámicas tardorromanas y altomedievales en la Península Ibérica, Anejos del Archivo Español de Arqueología, XXVIII (II Simposio de Arqueología. Mérida 2001), Madrid, pp. 119-168.

GUTIÉRREZ LLORET, S., MORET, P., ROUILLARD, P. y SILLIÉRES, P. (1998-1999): "Le peuplement du bas Segura de la protohistoire au moyen age (prospections 1989-1990)", Lvcentvm, XVII-XVIII, pp. 25-74.

HILTON, R. (1985): Siervos liberados. Los movimientos campesinos medievales y el levantamiento inglés de 1381, Madrid.

ÍNIGUEZ SÁNCHEZ, Ma. C. y MAYORGA MAYORGA, J. F. (1993): "Un alfar emiral en Málaga”, La cerámica altomedieval en el sur de al-Andalus, Granada, pp. 117-138.

JIMÉNEZ CASTILLO, P. (2013): Murcia. De la Antigüedad al Islam, Director: Julio Navarro Palazón, Tesis doctoral, Universidad de Granada. http://digital.csic.es/handle/10261/95860

JIMÉNEZ CASTILLO, P. (2016): "La ciudad y el reino de Murcia durante el siglo XI”, Cuando Almería era Almariyya, Almería, pp. 151-204.

JIMÉNEZ CASTILLO, P. y NAVARRO PALAZÓN, J. (1997): Platería 14. Sobre cuatro casas andalusíes y su evolución (siglos X-XIII), Murcia.

LÓPEZ PADILLA, J. A. y XIMÉNEZ DE EMBÚN SÁNCHEZ, T. (2008): "Excavaciones arqueológicas en el yacimiento emiral de Cabezo Pardo (San Isidro-Granja de Rocamora, Alicante). Primeros resultados", Lvcentvm, XXVII, pp. 175-164.

MALPICA CUELLO, A., JIMÉNEZ PUERTAS, M. y CARVAJAL LÓPEZ, J. C. (2010): "Estudio de la cerámica de Madinnat Ilbīra (Cerro del Sombrerete, Atarfe)", Anuario Arqueológico de Andalucía. 2006, Sevilla, pp. 1838-1850.

MARTÍNEZ RODRÍGUEZ, A. y PONCE GARCÍA, J. (1995a): "El horno califal de la calle Rojo, Lorca", Verdolay, 5, pp. 143-155.

MARTíNEZ RODRÍGUEZ, A. y PONCE GARCÍA, J. (1995b): "Excavaciones arqueológicas de urgencia en la calle Eugenio Úbeda. 12-14 (Lorca, Murcia)", Memorias de Arqueología 8. 1993, Murcia, pp. 298-329.

MAZZOLI-GUINTARD, Ch. (1996): Villes d'al-Andalus. L'Espagne et le Portugal à l'époque musulmane (VIIle-XVe siècles), Rennes.

MELERO GARCÍA, F. (2009): "El vertedero medieval de Cártama, Málaga: la cerámica de los pozos de época emiral y califal", Arqueología y territorio medieval, 16, pp. 33-52. 
MENÉNDEZ FUEYO, J. L. (2004): “La cerámica de la Rábita Califal", El ribāt califal. Excavaciones e investigaciones (1984-1992), Madrid, pp. 89-130.

MOLERA, J., PRADELL, T., SALVADÓ, N. y VENDRELL-SAZ, M. (2009): "Lead Frits in Islamic and Hispano-moresque Glazed Productions", From Mine to Microscope. Advances in the Study of Ancient Technology, Oxford, pp. 11-22

MOTOS GUIRAO, E. (1993): "La cerámica altomedieval de El Castillón (Montefrío, Granada)", La cerámica medieval en el sur de al-Andalus, Granada, pp. 208-237.

MUÑOZ LÓPEZ, F. y CASTAÑO BLÁZQUEZ, T. (1993): "El alfar islámico de la calle Pedro de la Flor”, Verdolay, 5, pp. 157-169.

MURCIA MUÑOZ, A. J. y GUILLERMO MARTÍNEZ, M. (2003): "Cerámicas tardorromanas y altomedievales procedentes del teatro romano de Cartagena", Cerámicas tardorromanas y altomedievales en la Península Ibérica, Anejos del Archivo Español de Arqueología. XXVIII (II Simposio de Arqueología. Mérida 2001), Madrid, pp. 169-223.

NAVARRO PALAZÓN, J. (1986): La cerámica islámica en Murcia. I Catálogo, Murcia.

NAVARRO PALAZÓN, J. (1990): "Los materiales islámicos del alfar antiguo de San Nicolás de Murcia”, Fours de potiers et «testares» médiévaux en Méditerranée occidentale, Madrid, pp. 29-44.

NAVARRO PALAZÓN J. y GARCÍA AVILÉS, A. (1989): "Aproximación a la cultura material de Madinat Mursiya”, Murcia musulmana, Murcia, pp. 253-356.

PASCUAL PACHECO, J., RIBERA I LACOMBA, A., ROSELLÓ MESQUIDA, M. (2003): "Cerámicas de la ciudad de Valencia entre la época visigoda y omeya (siglos VI-X)", Cerámicas tardorromanas y altomedievales en la Península Ibérica, Anejos del Archivo Español de Arqueología, XXVIII (II Simposio de Arqueología. Mérida 2001), Madrid, pp. 67-117.

PÉREZ ALVARADO, S. (2003): Las cerámicas omeyas de Marroquíes Bajos. Un indicador arqueológico del proceso de islamización, Jaén.

PÉREZ ALVARADO, S., MONTILLA TORRES, I., SALVATIERRA CUENCA, V. y CASTILLO ARMENTEROS, J. C. (2003): "LaS primeras cerámicas de Marroquíes Bajos (Jaén) entre la Tardoantigüedad y el Islam", Cerámicas tardorromanasy altomedievales en la Península Ibérica, Anejos del Archivo Español de Arqueología, XXVIII (II Simposio de Arqueología. Mérida 2001), Madrid, pp. 389-410.

PÉREZ BOTÍ, G. (2014): “La caracterización de la cerámica islámica de El Castellar de Alcoi (Alicante) de finales del siglo IX y siglo X: El Horizonte Castellar I", Recerques del Museu d'Alcoi, 22/23, pp. 53-68.
PICON, M.; THIRIOT, J., VALLAURI, L. (1995): "Techniques, évolutions et mutations", Le vert \& le brun, Marsella, pp. 41-50.

RIERA, M. (1999): "Cerámicas emirales y califales halladas en Mallorca", Arqueología y Territorio Medieval, 6, pp. 177-190.

ROSSELLÓ BORDOY, G. (1987): "Algunas observaciones sobre la decoración cerámica en verde y manganeso", Cuadernos de Madinat al-Zahrā', I, pp. 125-137.

ROSSELLÓ BORDOY, G. (2002): "Iliberis / Ilbira: cerámica califal y sus producciones periféricas", Estudios sobre Patrimonio, Cultura y Ciencias medievales, 3-4, pp. 173186.

ROSSER LIMIÑANA, P. (1994): "La ciudad de Alicante y la arqueología del poblamiento en época medieval islámica", LQNT, 2, pp. 111-146.

SALADO ESCAÑO, J. B.; NAVARRO LUENGO, I. y SUÁREZ PADILLA, J. (2011): "La cerámica islámica altomedieval de Melilla", La céramique maghrébine du haut moyen age (VIIle-Xe siècle), Roma, pp. 63-85.

SALINAS, E. (2013): "Cerámica vidriada de época emiral en Córdoba”, Arqueología y Territorio Medieval, 20, pp. 67-96.

SUÁREZ, J.; FERNÁNDEZ, L. E.; NAVARRO, I.; CISNEROS, M. I. y MAYORGA, J. (2003) "El registro arqueológico para la Málaga emiral. Una rápida revisión de los datos disponibles", Mainake, XXV, pp. 21-32.

VALLEJO TRIANO, A. y ESCUDERO ARANDA, J. (1966): "Aportaciones para una tipología de la cerámica común califal de Madinat al-Zahrā", Arqueología y territorio medieval, 9, pp. 133-176.

GOMES, R. (1992): "Cerâmicas muçulmanas de Silves, dos séculos VIII e IX", Actas das las Jornadas de Cerâmica medieval e Pós-medieval, Tondela, pp. 19-32.

WATSON, O. (2014): "Revisiting Samarra: the Rise of Islamic Glazed Pottery”, Beiträge zur Islamischen Kunst und Archäologie, Wiesbaden, pp. 123-142.

ZOZAYA, J. (1980a): "Aperçu générale sur la céramique espagnole”, La céramique médiévale en Mediterranée Occidentale, Paris, pp. 265-296.

ZOZAYA, J. (1980b): "Essai de chronologie pour certains types de céramique califale andalouse", La céramique médiévale en Mediterranée Occidentale, Paris, pp. $311-$ 315. 